UNIVERSIDADE DE SÃO PAULO

INSTITUTO DE PSICOLOGIA

\title{
A influência do contexto social não aversivo na percepção da dor: uma abordagem comportamental
}

FERNANDO RODRGUES LEITE

São Paulo

2021 


\title{
FERNANDO RODRIGUES LEITE
}

A influência do contexto social não aversivo na percepção da dor: uma abordagem comportamental

\author{
Versão corrigida
}

Dissertação apresentada ao Instituto de Psicologia da Universidade de São Paulo para obtenção do título de Mestre em Ciências.

Área de Concentração: Neurociências e

\section{Comportamento}

Orientador: Prof. Dr. Guilherme de Araújo Lucas

São Paulo 
Nome: LEITE, Fernando Rodrigues

Título: A influência do contexto social não aversivo na percepção da dor: uma abordagem comportamental

Dissertação apresentada ao Instituto de Psicologia da Universidade de São Paulo para obtenção do título de Mestre em Ciências.

Aprovado em:

Banca Examinadora

Prof. Dr.

Instituição:

Julgamento:

Prof. Dr.

Instituição:

Julgamento:

Prof. Dr.

Instituição: 
Julgamento: 


\section{AGRADECIMENTO}

Agradeço primeiramente ao Senhor Deus, por ter me concedido saúde, força e disposição para vencer essa etapa de minha vida. Do mesmo modo sou grato ao Senhor por ter dado saúde aos meus familiares e abrandado o meu espírito nos momentos mais difíceis de minha jornada acadêmica até este momento.

De forma mais profunda agradeço a minha esposa Amanda Lopes de Lima Leite, que jamais me negou apoio e incentivo, incondicionalmente sempre permaneceu ao meu lado. Obrigado pelo companheirismo e paciência. Igualmente, minha filha Andressa Lopes Leite, uma das minhas maiores motivações, agradeço pela compreensão da minha ausência em momentos de brincadeiras e diversão.

Sou grato a todos os professores que contribuíram com a minha trajetória acadêmica, especialmente ao Prof. Dr. Guilherme de Araújo Lucas, responsável pela orientação do meu projeto. Manifesto aqui minha gratidão por sua confiança e por compartilhar sua sabedoria, seu tempo e sua experiência. De modo análogo, agradeço ao Prof. Dr. Gelson Genaro, principal motivador de meu ingresso na área acadêmica. Obrigado por colaborar sempre com sábias recomendações ante as diversas tribulações da investigação científica.

Agradeço especialmente, aos meus pais, Aguinaldo Alves Leite e Neide Aparecida Rodrigues, que tanto se esforçaram pelo amparo de minha educação e nunca resignaram minha proteção.

Agradeço a todos que participaram desta pesquisa, de maneira especial, agradeço à Sônia Zanon e Andrea Carvalho, pela colaboração e disposição constante. 
AUTORIZO A REPRODUÇÃO E DIVULGAÇÃO TOTAL OU PARCIAL DESTE

TRABALHO, POR QUALQUER MEIO CONVENCIONAL OU ELETRÔNICO,

PARA FINS DE ESTUDO E PESQUISA, DESDE QUE CITADA A FONTE.

Catalogação na publicação

Biblioteca Dante Moreira Leite

Instituto de Psicologia da Universidade de São Paulo

Dados fornecidos pelo(a) autor(a)

Rodrigues Leite, Fernando

A influência do contexto social não aversivo na percepção da dor: uma abordagem comportamental. / Fernando Rodrigues Leite; orientador Guilherme de Araujo Lucas. -- São Paulo, 2021.

$51 \mathrm{f}$.

Dissertação (Mestrado - Programa de Pós-Graduação em Neurociências e Comportamento) -- Instituto de Psicologia, Universidade de São Paulo, 2021.

1. Dor. 2. Contexto social. 3. Comportamento nocifensivo. 4. Nocicepção. I. de Araujo Lucas, Guilherme, orient. II. Título. 



\section{RESUMO}

LEITE, Fernando Rodrigues. A influência do contexto social não aversivo na percepção da dor: uma abordagem comportamental. 2019. Dissertação (Mestrado em Neurociências e Comportamento) Instituto de Psicologia Universidade de São Paulo, São Paulo, 2021.

Além de ser uma experiência sensorial, a dor apresenta componentes emocionais, cognitivos e sociais determinantes para a sua interpretação pelo sistema nervoso central. Há uma complexa relação entre o ambiente psicossocial e a percepção da dor, entretanto os mecanismos de comunicação social da dor ainda são pouco conhecidos. O objetivo do presente estudo foi investigar a influência de diferentes contextos sociais não-aversivos sobre a percepção da dor. Avaliamos a influência da presença de gênero oposto, da relação mãe/prole e pai/prole e da presença de irmãos do mesmo gênero na resposta nocifensiva induzida pela administração de formalina 5\%. Todos os protocolos experimentais foram, previamente, aprovados pelo Comitê de Ética da Faculdade de Medicina de Ribeirão Preto - Universidade de São Paulo (FMRPUSP). Foram usados camundongos adultos e recém-nascidos da linhagem Balb/C de ambos os sexos. O estímulo doloroso foi provocado pela administração intraplantar de $40 \mu \mathrm{l}$ de formalina $5 \%$. Os comportamentos nocifensivos (número de sacudidas e tempo de lambida da pata injetada) foram avaliados em duas fases: fase 1 (10 minutos após a injeção) e fase 2 (50 minutos finais). Os paradigmas usados foram: (a) macho com dor na presença do coespecífico fêmea, fêmea com dor na presença do coespecífico macho; (b) macho pai com dor na presença da prole, fêmea mãe com dor na presença da prole; (c) macho com dor na presença de um irmão, fêmea com dor na presença de uma irmã. Ainda além, foi investigado a interferência da dor na hierarquia de dominância, na qual foi avaliado o tempo gasto pelo dominante para expulsar do tubo cada subordinado: (d) macho dominante e fêmea dominante foi submetido a estimulação dolorosa mediante administração de $40 \mu 1$ de Adjuvante Completo de Freund (CFA), substância capaz de promover dor persistente. Os resultados foram avaliados por Análise de Variância de uma via e cada grupo experimental teve 10-12 animais. Diferença entre os grupos foi considera significativa quando $p<0,05$. Assim, foi demonstrado que na presença da fêmea, machos manifestaram menos comportamento nocifensivo, tanto na 
fase 1, quanto na fase 2. De maneira semelhante, as fêmeas apresentaram menos resposta nocifensiva na presença do macho. No número de sacudidas, a diferença ocorreu na primeira fase, enquanto que no tempo de lambida a diferença se deu nas duas fases. Na presença da prole, o número de sacudidas dos machos não foi diferente dos animais submetidos à dor isoladamente. Entretanto, o tempo de lambida foi reduzido apenas na fase 1. As fêmeas submetidas ao estímulo nociceptivo na presença da prole apresentaram menos resposta nocifensiva em ambas as fases, tanto em relação ao número de sacudidas, quanto ao tempo de lambida. Quando na presença do irmão/irmã, o número de sacudidas não foi, significativamente, diferente do grupo que experimentou a dor em isolamento. Entretanto, quando medido o tempo de lambida, a fêmea na presença de uma irmã apresentou uma redução na resposta nocifensiva. Tanto macho, quanto fêmea dominante, não apresentou diferença no tempo de expulsão dos subordinados após a estimulação dolorosa. Estes resultados inferem que o contexto social relacionado ao gênero oposto, à prole e à presença de coespecífico familiar são determinantes para a interpretação da experiência dolorosa em camundongos, e podem ser usados como modelos experimentais para investigação de circuitos neurais específicos relacionados aos componentes sociais que influenciam a percepção do estímulo nociceptivo.

Palavras-chave: Contexto social. Comportamento nocifencivo. Dor. Nocicepção. 
LEITE, Fernando Rodrigues. The influence of non-aversive social context on pain perception: a behavioral approach. 2021. Dissertation (Master in Neurosciences and Behavior) Institute of Psychology University of São Paulo, São Paulo, 2021.

In addition to being a sensory experience, pain has emotional, cognitive and social components that are crucial for its interpretation by the central nervous system. There is a complex relationship between the psychosocial environment and pain perception, however the pain communication mechanisms are still poorly known. The aim of the present study was to investigate the influence of different non-aversive social contexts on pain perception. We evaluated the influence of the presence of opposite gender, the relationship mother / offspring and father / offspring and the presence of siblings of the same gender on the nociceptive response induced by $5 \%$ formalin administration. All experimental protocols were previously approved by the Ethics Committee of the Ribeirão Preto Medical School University of São Paulo (FMRP-USP). Adult and newborn Balb / C mice of both sexes were used. Painful stimulation was caused by intraplantar administration of $40 \mu \mathrm{l}$ of $5 \%$ formalin. Nochensive behaviors (number of jolts and injected paw licking time) were evaluated in two phases: phase 1 (10 minutes after injection) and phase 2 (final 50 minutes). The paradigms used were: (a) male with pain in the presence of female co-specific, female with pain in the presence of male co-specific; (b) male father with pain in the presence of offspring, female mother with pain in the presence of offspring; (c) male in pain in the presence of a brother, female in pain in the presence of a sister. In addition, the interference of pain in the dominance hierarchy was investigated, in which the time spent by the dominant to expel each subordinate from the tube was evaluated: (d) dominant male and dominant female underwent painful stimulation by administering $40 \mu \mathrm{l}$ of Complete Adjuvant de Freund (CFA), a substance capable of promoting persistent pain. Results were evaluated by one-way analysis of variance and each experimental group had 10-12 animals. Difference between groups was considered significant when $\mathrm{p}<0.05$. Thus, it was demonstrated that in the presence of the female, males showed less noxious behavior, both in phase 1 and phase 2. Similarly, females 
showed less noxious response in the presence of male. In the number of jolts, the difference occurred in the first phase, while in the licking time the difference was in the two phases. In the presence of offspring, the number of male jolts was not different from the animals submitted to pain alone. However, the licking time was reduced only in phase 1. Females submitted to nociceptive stimulation in the presence of offspring showed less noxious response in both phases, both in relation to the number of shakes and the licking time. When in the presence of brother / sister, the number of jolts was not significantly different from the group that experienced pain in isolation. However, when the licking time was measured, the female in the presence of a sister showed a reduction in nocifensive response. Both male and dominant female showed no difference in the time of expulsion of subordinates after painful stimulation. These results show that the social context related to the opposite gender, the offspring and the presence of family co-specific are determinant for the interpretation of painful experience in mice, and can be used as experimental models for investigation of specific neural circuits related to the social components that influence the perception of nociceptive stimulus.

Keyword: Social context. Nociceptive behavior. Pain. Nociception. 


\section{LISTA DE FIGURAS}

Figura 1 -Fêmea* isolada x macho* isolado (número de sacudidas)...................................26

Figura 2 - Fêmea* isolada x macho* isolado (tempo de lambida)........................................27

Figura 3 - Macho* isolado x macho* + irmão (número de sacudidas). .................................28

Figura 4 - Macho* isolado x macho* + irmão (tempo de lambida) ........................................28

Figura 5 - Fêmea* isolada x Fêmea* + irmã (número de sacudidas).....................................29

Figura 6 - Fêmea* isolada x Fêmea* + irmã (tempo de lambida)..........................................29

Figura 7 - Macho* isolado x macho* + fêmea (número de sacudidas). $\quad$.........................30

Figura 8 - Macho* isolado x macho* + fêmea (tempo de lambida)........................................31

Figura 9 - Fêmea* isolada x fêmea* + macho (número de sacudidas) ...................................31

Figura 10 - Fêmea* isolada x fêmea* + macho (tempo de lambida) .........................................32

Figura 11 - Fêmea* + macho: ciclo estral x número de sacudidas........................................33

Figura 12 - Fêmea* + macho: ciclo estral $x$ tempo de lambida.............................................33

Figura 13 - Macho* + fêmea: ciclo estral x número de sacudidas.........................................34

Figura 14 - Macho* + fêmea: ciclo estral x tempo de lambida.............................................34

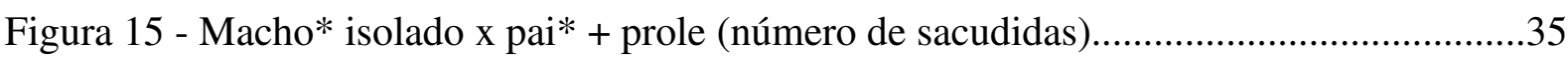

Figura 16 - Macho* isolado x pai* + prole (tempo de lambida) ...........................................36

Figura 17 - Fêmea* isolada x mãe* + prole (número de sacudidas) ......................................36

Figura 18 - Fêmea* isolada x mãe* + prole (tempo de lambida) ...........................................37

Figura 19 - Macho* dominante x subordinados (tempo de expulsão)....................................38

Figura 20 - Fêmea* dominante x subordinadas (tempo de expulsão)....................................38 


\section{SUMÁRIO}

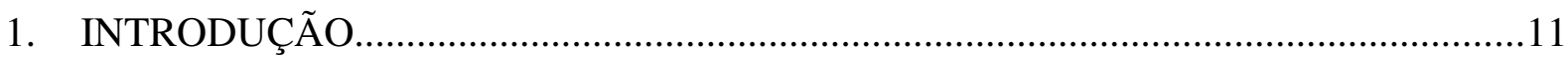

$1.1 \quad$ DOR

1.2 MODULAÇÃO SOCIAL DA DOR E CONDICIONAMENTO CONTEXTUAL. .12

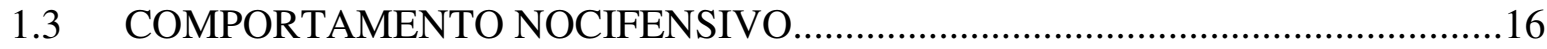

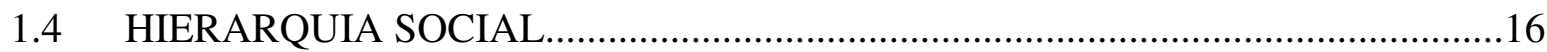

1.5 TESTE DO TUBO

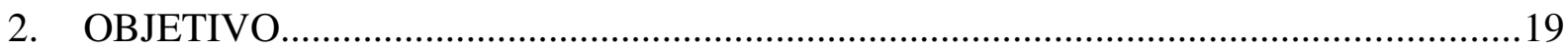

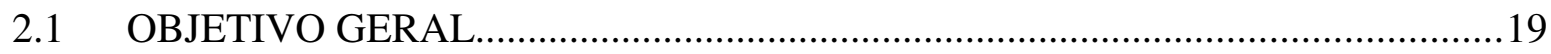

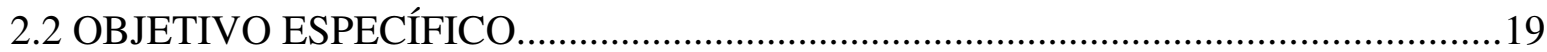

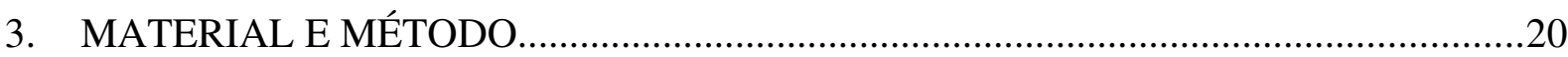

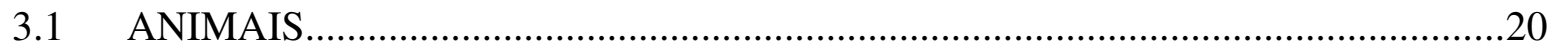

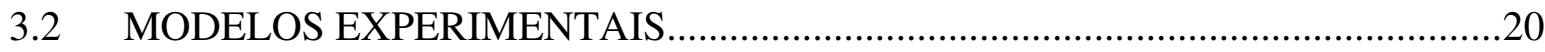

3.2.1 Paradigma 1: influência do gênero oposto na manifestação da dor....................20

3.2.2 Paradigma 2: influência da prole sobre a manifestação de dor..........................22

3.2.3 Paradigma 4: influência do parentesco de irmãos sobre a manifestação de dor. 22

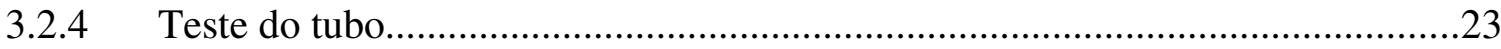

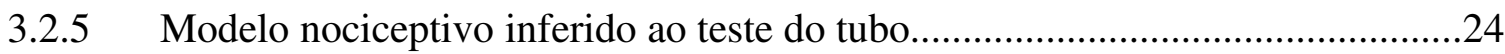

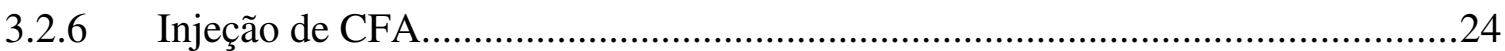

3.2.7 Avaliação das respostas nocifensivas............................................................24

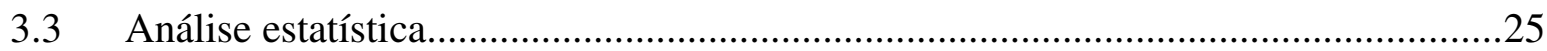

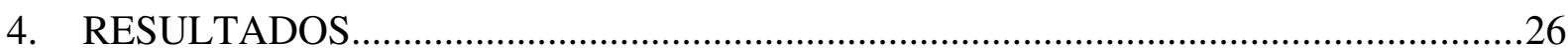

5. DISCUSSÃO

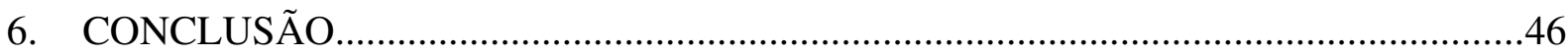

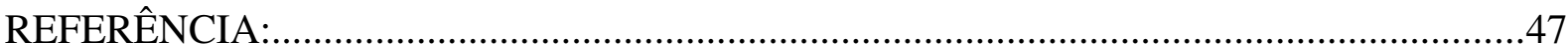





\section{INTRODUÇÃO}

\subsection{DOR}

Essencialmente, a dor configura-se em um mecanismo fisiológico de proteção, de tal maneira advertindo o indivíduo, de sua integridade física, substancializando deste modo, estímulos nocivos potencialmente capazes a ocasionar lesões teciduais em organismos vivos (Treede, 2018). Por outro lado, a dor perde seu papel de alerta e proteção, ao passo que modificações em suas vias sensoriais culminam em quadros de hipersensibilidade, por conseguinte tornando-se um problema persistente e debilitante ao indivíduo que a vivencia (Mcdermott et al., 2006; Basbaum et al., 2009).

Os mecanismos de nocicepção estão relacionados a uma rede de fibras aferentes, que assumem o papel de transmitir informações ao sistema nervoso central (SNC), por meio da condutividade elétrica nervosa, frente a estímulos ambientais potencialmente lesivos, como por exemplo, queimadura, trauma e o contato direto com substâncias ácidas, que respectivamente representam o estímulo térmico, mecânico e químico da nocicepção (Basbaum et al., 2009).

Em conformidade, a sensação de dor, tão somente sob concepções fisiológicas, é reconhecida pelo termo nocicepção, em que neurônios de primeira ordem, associados a nociceptores transformam o estímulo nocivo, em potencial de ação que se propaga ao corpo celular, no gânglio dorsal da medula espinal, estabelecendo sinapses junto a neurônio de segunda ordem, no corno dorsal da medula espinal. Por conseguinte, projeta seus axônios via trato espino-talâmico ao tálamo, onde projeções ocorrem mediante neurônios de terceira ordem ao giro pós-central do córtex, região responsável pelo processamento somatotópico da informação nociceptiva (Riedel e Neeck, 2001).

As fibras sensoriais, fundamentalmente, classificam-se em fibras do tipo C nãomielinizadas e fibras do tipo A mielinizadas, subdivididas em $\mathrm{A} \beta$ mecanosensitivas e $\mathrm{A} \delta$ nociceptivas às quais diferem essencialmente quanto à velocidade da transmissão do impulso elétrico quando estimuladas. Sendo assim, as fibras tipo Aס assumem o papel de transmitir o estímulo doloroso de forma rápida, ou também designado agudo, enquanto que as fibras do tipo $\mathrm{C}$ o fazem de forma mais lenta. Isto se deve ao fato das fibras do tipo A possuírem uma especificidade em sua constituição anatômica, a bainha de mielina, que lhe confere a 
capacidade de propagar potenciais de ação efetivamente mais rápidos, ao passo que as fibras do tipo $\mathrm{C}$ não a possuem, tornando seu impulso nervoso mais tardio. Já as fibras $\mathrm{A} \beta$, também mielinizadas, são responsivas unicamente ao estímulo sensorial tátil e não nociceptivo (ROCHA et al., 2007). Fibras do tipo C, são ainda encarregadas da transmissão do estímulo doloroso mediante liberação de componentes químicos endógenos em condição de injúria tecidual. Desses, destacam a histamina, a prostaglandina, a bradicinina e a substância P. Dessa forma, atuam diretamente na sensibilização destas fibras, conferindo-lhe a denominação de estímulo doloroso polimodal (Johanek et al., 2008).

\subsection{MODULAÇÃO SOCIAL DA DOR E CONDICIONAMENTO CONTEXTUAL}

A dor é qualificada por "Uma experiência angustiante associada a um dano tecidual real ou potencial com componentes sensoriais, emocionais, cognitivos e sociais" (Williams e Craig, 2016). Em vista disso, a dor faz alusão a uma circunstância de natureza multidimensional, com envolvimento de fatores étnicos, culturais, socioeconômicos, afetivos e ainda relacionados ao gênero, portanto não somente os eventos físicos e sensoriais que integram a dor têm sido considerados no campo científico. Por conseguinte, aspectos como emoção e cognição também obtiveram destaque na melhor compreensão da dor (Bushnell et al., 2013).

Em consonância, pesquisadores propuseram um padrão de processamento sensorial da dor, distribuído em quatro estágios genéricos (Wade et al., 1996). O primeiro, constitui-se da discriminação sensorial, responsável por exprimir localização espacial, momento e propriedades de uma aguda sensação dolorosa. Um segundo estágio é o desconforto, quase sempre seguido de transtorno emocional, devido à abrupta e invasiva sensação de dor. Este estágio, em específico, realça a direta resposta concernente à dor do indivíduo em relação à sensação provocada pelo estímulo nociceptivo, ou ainda associado ao caráter do estímulo. Uma dor oriunda de lesão repentina, percebida de maneira aguda, qual expressa o grau de sofrimento experimentado como uma condição comprometedora à integridade, tanto física, quanto emocional do indivíduo. Em síntese, elementos como depressão, ansiedade e medo exercem domínio sob sua total consciência momentânea. Tal relação para com a dor implica em uma análise de caráter cognitivo, apontando influências relacionadas à personalidade do indivíduo (Harkins et al., 1989; Wade et al., 1992). 
O terceiro estágio de processamento da dor está situado acerca de uma proeminente atividade cognitiva, exercendo assim, influência direta na percepção de efeitos reais ou ainda imaginários de uma dor persistente. Isto se dá em decorrência de crenças, ou convicções pessoais, de tal maneira a influir ante ao modo em que se encara o sofrimento doloroso. Haja vista a existência de duas perspectivas distintas à factual condição dolorosa, sendo uma emocional, por exemplo, depressão, ansiedade, frustração, medo e raiva, já outra ideológica como, capacidade de suportar a dor, interferência do estilo de vida ante a percepção, capacidade de autocontrole e ainda o grau de probabilidade de cura (Wade e Hart, 2002), o que pode ser ilustrado pela similar intensidade de dor vivenciada por duas mulheres, porém em circunstâncias distintas, na qual uma se encontra no pleno esforço do trabalho de parto e outra por decorrências de um câncer. Ainda que a intensidade da sensação de dor venha a ser semelhante para ambas, o contexto referente às duas formas de dor distingue-se notoriamente. Dessa maneira, é presumível que as duas passem por dissemelhantes manifestações de ansiedade, medo, frustração, irritação e depressão. Logo, suas concepções para com a dor serão antagônicas, em virtude da expectativa de alívio da percepção dolorosa ante o decurso final desse quadro e ainda a execução de autocontrole acerca da atenuação do sofrimento da dor (Wade et al., 1996).

Por fim, o quarto estágio de processamento da dor, o qual é compreendido pela exteriorização de padrões comportamentais concernentes ao quadro de dor, os quais tonam-se evidentes por meio de sinais como baixa produtividade no trabalho, decréscimo de atividades cotidianas, semblante de padecimento e resguardo corporal correspondente a parte afetada. Em síntese, este paradigma ressalta a presteza da atividade cognitiva ante a sensação de dor, em razão da análise crítica dos fatores de campo social, antes mesmo de intercorrências comportamentais (Price et al., 1986; Wade et al., 1996; Price et al., 1999).

Nesse sentido, outros componentes como a matriz neural também determinam as qualidades sensoriais da dor, preditas por fatores genéticos responsáveis pelo esboço da circuitaria sináptica. Assim, destacam núcleos somatossensoriais límbicos e tálamo-corticais exercendo papel importante nas discriminações sensoriais da dor, em paralelo à aferências emocionais e cognitivas, ao ponto de desencadear modulações inibitórias descendentes, prenunciando comportamentos de adaptação à condição dolorosa (Melzack, 1999). Assim também, experiências contextuais assimiladas podem tanto intensificar quanto diminuir a percepção de um estímulo doloroso, mediante a modulação da atividade de nociceptores em 
distintos núcleos do neuro-eixo. Ademais, estudos apontam para evidências acerca da existência de vias neurais comuns, entre experiências de dor física e experiência de "dor social", a dor vinculada a determinado contexto social, por exemplo, experiências como exclusão, perdas e conflitos sociais. Tais estudos são confirmados por ressonância magnética, assim atividades de áreas cerebrais, como córtex anterior singular, córtex pré-frontal, foram observadas em paradigmas de dor com envolvimento social, identificado do contexto de exclusão em sociedade (Eisenberger et al., 2003).

Foi observado em estudo desenvolvido com humanos conjuges, uma associação entre relacionamento conjugal, depressão e severidade da dor. Interessantemente, o conjuge, que venha fornecer amparo emocional ao parceiro que se encontra em desconforto doloroso, pode automática e involuntariamente reforçar a percepção de desconforto do outro, ao passo que reagindo negativamente ou ignorando o comportamento de dor, o mesmo pode ser amenizado, ou até mesmo abolido. Sugerindo um modelo de retroalimentação ao comportamento doloroso, bem como à relevância deste contexto para a melhor compreensão das múltiplas facetas da dor (Leonard et al., 2006). Em consonância, indivíduos condicionados, mediante o fornecimento de pistas a um subsequente estímulo doloroso, trazem uma percepção de dor muito maior em relação aqueles desprovidos de pistas (Ploghaus et al., 1999; Sawamoto et al., 2000; Ploghaus et al., 2001).

Sob outra perspectiva, indicativos contextuais podem ainda elevar ou até mesmo reduzir o dinamismo de neurônios nociceptivos na coluna dorsal da medula espinal, inclusive na ausência de um estímulo de caráter aversivo. Antagonicamente, evidências apontam o condicionamento não-aversivo como potencial modulador da percepção dolorosa. Por exemplo, a medida em que o foco de atenção é deslocado, a intensidade da experiência dolorosa pode ser reduzida, ao passo que centralizando a atenção no estímulo doloroso, sua percepção pode tonar-se exacerbada (Villemure e Bushnell, 2002). Paralelamente, inferências de emoções ante percepção de dor têm ganhado destaque no campo da pesquisa neurocientífica. Sensações como ansiedade, humor, estresse e emoções, tanto negativas quanto positivas, imperam influentemente sob a interpretação de um estímulo doloroso, determinando tanto a atenuação, quanto o agravamento da experiência dolorosa (Jennings et al., 2014). Em vista disso, o efeito do contexto psicossocial positivo no resultado terapêutico, mediante efeito de placebo como modelo, tem sido investigado por diversos estudos nos últimos anos (Colloca e Benedetti, 2005; Benedetti, 2014). Dessa maneira, diferentes 
estímulos integram o contexto psicossocial positivo, tanto sensoriais, quanto sociais, sofrendo ainda incorporação de elementos internos, como expectativas, motivação, ansiedade, caráter psicológico e personalidade (Price e Barrell, 2000; Geers et al., 2007; Price et al., 2008).

Em outra perspectiva, modelos de dor animal envolvendo paradigmas sociais evidenciaram alterações no comportamento doloroso de camundongos dispostos em duplas, decorrendo, tanto de amplificações, quanto de reduções, durante o tempo em que estes mantiveram contato. Dessa forma, conferindo um efeito modulatório da dor, o qual intercorre dá incitação ambiental, mediada, neste caso, a um determinado contexto social. Desse modo, se observou a manifestação do contágio emocional, em que a sensibilidade ao estímulo nociceptivo foi aumentada no camundongo que se mantinha sob estimulo doloroso concomitantemente à observação do parceiro de gaiola (animais que conviveram em grupo por período mínimo de sete dias), que também estava sob estimulação dolorosa. Todavia, esta modulação social não foi observada no animal que sob efeito de dor se mantinha junto a indivíduos estranhos, isto é, que nunca mantiveram qualquer tipo de contato prévio.

Diante disso, constata-se em camundongos, indicativos de empatia para com o outro, no que se refere a condições de dor. Ademais, estes mesmos autores observaram que a inferência social da dor é substancialmente vinculada às circunstâncias que se pautam na companhia de um amigo ou companhia de um estranho. Isto se deve ao fato de que o camundongo macho com dor, junto a outro camundongo estranho, porém sem dor, apresentou significativo decréscimo em seu comportamento doloroso, salientando um caráter de transmissão social, exclusivamente mediado por camundongos já familiarizados entre si (Langford et al., 2006). Nesse ínterim, novas investigações foram oferecidas a fim de ampliar o entendimento acerca da modulação social sobre a dor. Por conseguinte, mostrando uma tendência exclusiva de camundongos fêmeas a se aproximarem de um colega de caixa que esteja expressando comportamento de dor, ao passo que para o colega de caixa em condições normais, isto é, sem dor, bem como para fêmeas estranhas entre si, isto não acontece, fato este não verificado em camundongos machos, que não demonstraram qualquer discriminação a respeito (Langford et al., 2010).

Em síntese, o estudo do contexto disponibiliza uma importância adicional junto ao manejo clínico da dor, podendo ainda revelar-se como um potencial suplemento a efetividade nos diferentes tratamentos de dor (Bushnell et al., 2013). Neste projeto, investigaremos, em um modelo experimental, como a exposição a diferentes contextos influenciam a percepção da 
dor. As hipóteses a serem testadas são: (1) a presença do gênero oposto durante experiência de dor é mais relevante, tanto para o macho, quanto para à fêmea, (2) a presença de um irmão de mesmo gênero é relevante para a fêmea assim como para o macho, (3) a presença da prole durante experiência de dor aguda é mais pertinente para a fêmea mãe do que para o macho pai e (4) no decorrer da dor inflamatória o comportamento de dominância pode ser afetado.

\subsection{COMPORTAMENTO NOCIFENSIVO}

O comportamento nocifensivo é representado pela resposta animal, evocada por estímulos que ativam o sistema nociceptivo, estando associados a um mecanismo automático de proteção contra injúrias e lesões (GEBHART, 2007).

O teste de formalina é um modelo de dor animal realizado com o princípio básico, formaldeído. A formalina é qualificada como substância pró-nociceptiva, assim o teste é feito com injeção subcutânea no dorso da pata animal e evoca uma série de comportamentos motores, estereotipados, alusivos à nocicepção. Sugerindo a presença de dor. O ato de lamber, morder e sacudir a pata afetada, são exemplos destes comportamentos (Dubuisson e Dennis, 1977; Hunskaar et al., 1985; Porro e Cavazzuti, 1993; Yaksh et al., 2001). Acresce que, o comportamento nocifensivo, neste modelo é expresso de modo bifásico, em virtude de haver um breve período preliminar, que consiste da duração de 5 a 10 minutos (fase 1), em que, por conseguinte há uma interfase caracterizada da remitência do comportamento doloroso, seguida de um período, agora maior de manifestação nocifensiva e ainda mais fortalecida, constituído de 20 a 40 minutos (fase 2) (Dubuisson e Dennis, 1977).

Neste modelo, estudos prévios apontam discriminações entre as duas fases do comportamento nocifensivo, sendo a primeira fase de caráter agudo e a segunda inflamatório. Em vista disso, é conferido à primeira fase a predominância, bem como a direta estimulação de nociceptores primários do tipo-C, ao passo que a segunda fase é atribuída a sensibilização central, notadamente em neurônios do corno da raiz dorsal da medula espinal. Por conseguinte, os impulsos primários de aferentes cutâneos da fase inicial são requeridos para efetivação da segunda fase do comportamento nocifensivo (Coderre et al., 1990; Mccall et al., 1996; Fischer et al., 2014). Desse modo, o comportamento nocifensivo apresenta-se como 
conveniente instrumento para se avaliar as heterogeneidades que compõem a percepção dolorosa em modelo animal.

\subsection{HIERARQUIA SOCIAL}

A hierarquia social fundamenta-se na habilidade de organização em sociedade, competência desenvolvida pelos animais, inclusive humanos, no decorrer de sua evolução. Notadamente desempenhada numa demarcação entre aqueles que exercem dominância e outros subordinação, tendo por desígnio nos animais, a necessidade de assegurar a manutenção da própria espécie, assim como o controle de combates, e injúrias inconvenientes, proporcionando dessa forma, o equilíbrio social do grupo (Qu et al., 2017). No entanto, a hierarquia de dominância marca a incrementação de um contexto de desigualdade, em decorrência de que indivíduos dominantes delegam a si maior acesso a recursos, como alimentação, e acasalamento, guarnecidos ainda, de um caráter agressivo e intimidatório, além de uma tendência de possessividade a parceiros, bem como por demarcações territoriais específicas em seu habitat (Dunbar e Dunbar, 1977; Cole, 1981; Sapolsky, 2005; Arakawa et al., 2007; Wang et al., 2014; Qu et al., 2017).

Paralelamente, o padrão de hierarquia social nos seres-humanos é sobretudo conferido a status de ordem socioeconômica, em que a dominância se caracteriza, essencialmente dos seguintes aspectos: rendimento monetário, grau de escolaridade e posição social. Dessa maneira, torna-se o status socioêconomico um expressivo indicador de saúde e qualidade de vida, em virtude de sua influência a prognósticos de doenças do gênero cardiovascular, respiratório, reumático e psiquiátrico (Sapolsky, 2005). Em suma, o estresse originado deste contexto de submissão, encontra-se diretamente envolvido na elaboração de distintos desarranjos homeostáticos, em decorrência de adaptações orgânicas, tanto de ordem neuronais, quanto endócrinas, tendo como exemplo, hipertensão, resistência à insulina e imunossupressão, como resultado a crônicos e altos níveis sanguíneos de hormônios glicocorticoides (Adler et al., 2000; Sapolsky et al., 2000; Mackenbach, 2002; Sapolsky, 2005; Wang et al., 2014). 


\subsection{TESTE DO TUBO}

O comportamento de dominância social é marcadamente identificado pelo animal, que quando submetido a circunstâncias de confronto e desafio sai vitorioso. Por exemplo, disputas que envolvam recursos como alimento e demarcação de território entre membros de um mesmo grupo (Merlot et al., 2004).

O teste do tubo se configura em um modelo no qual é possível mensurar a propensão exclusiva de roedores a exercer o comportamento de dominância. $\mathrm{O}$ teste se assemelha muito à disputa por ocupação territorial entre dois animais. Neste, ambos frontalmente adentram o tubo por extremidades opostas, encontrando-se no centro do mesmo. O camundongo que pressionar o adversário para fora é apontado como vencedor, representando assim o dominante daquele território. Simultaneamente, aquele que recua para fora do tubo, é indicado como derrotado, denotando o comportamento de subordinação (Lindzey et al., 1961).

O teste do tubo tem várias vantagens, sendo de fácil execução, demandando apenas de um simples tubo plástico. Não implica em agressões físicas, o que reduz significativamente a incidência de lesões corporais. Além disso, os resultados são bem sólidos. Logo, praticamente todos roedores apresentam uma classificação em termos de hierarquia social neste teste. No entanto, o estresse oriundo da manipulação animal apresenta-se como fator limitante, portanto da importância à prévia habituação ao teste (Fan et al., 2019). Em vista disso, este trabalho enseja a análise da correlação de hieraquia social, coincidentemente a vulnerabilidade da condição nociceptiva. 


\section{OBJETIVO}

\subsection{OBJETIVO GERAL}

Estabelecer a influência do contexto social não aversivo na percepção da dor em camundongos por diferentes paradigmas, bem como investigar a implicação do processo nóxico na hierarquia de dominância.

\subsection{OBJETIVO ESPECÍFICO}

a) Avaliar a influência da presença de gênero oposto na percepção da dor.

b) Avaliar a influência da presença de irmão do mesmo gênero na percepção da dor.

c) Avaliar a influência da relação mãe/prole e pai/prole na percepção da dor.

d) Investigar a influência da dor na relação dominante/subordinado. 


\section{MATERIAL E MÉTODO}

\subsection{ANIMAIS}

Para execução deste projeto, foram utilizados camundongos de linhagem Balb/C, machos e fêmeas com 20-25g, procedentes do Biotério Central da Universidade de São Paulo, Campus de Ribeirão Preto (USP-RP), além de neonatos com uma semana de vida. Em cada gaiola foram mantidos cinco animais em ambiente com temperatura $\left(23-25^{\circ} \mathrm{C}\right)$ e umidade controladas, com ciclo claro/escuro de 12:12h (período claro a partir das 6:00h) e com livre acesso a ração e água. Os animais foram acondicionados no biotério de manutenção do Departamento de Farmacologia da Faculdade de Medicina de Ribeirão Preto/USP. Todos os experimentos foram regidos em uniformidade às diretrizes éticas da Associação Internacional para Estudo da Dor (IASP) e preliminarmente aprovados pelo Comitê de Ética local para uso de animais (CEUA - USP), protocolo no 206/2017.

\subsection{MODELOS EXPERIMENTAIS}

\subsubsection{Paradigma 1: influência do gênero oposto na manifestação da dor}

Grupo experimental 1: macho com estímulo nociceptivo na presença de uma fêmea. Os animais foram previamente adaptados ao ambiente experimental. Inicialmente, a fêmea foi colocada em gaiola sem maravalha por $30 \mathrm{~min}$, a fim de adaptá-la ao ambiente experimental e permitir que deixasse seu odor pela urina e fezes. Imediatamente após a retirada da fêmea, foi colocado na mesma caixa o macho, que ali permaneceu também por $30 \mathrm{~min}$. Este procedimento foi repetido duas vezes ao dia (manhã e tarde) por três dias consecutivos. Assim, os machos mantiveram contato exclusivamente olfatório com a respectiva fêmea. No $4^{\circ}$ dia (experimento), o mesmo procedimento foi repetido, iniciando com a colocação da fêmea em gaiola sem maravalha por 30 min. Após este período, à fêmea permaneceu na gaiola recebendo o macho previamente adaptado ao odor da respectiva fêmea. Entretanto, antes de ser colocado na gaiola com à fêmea, o macho foi submetido ao estímulo nociceptivo, 
mediante injeção subcutânea no dorso da pata esquerda de $40 \mu \mathrm{l}$ de formalina $5 \%$. A resposta nocifensiva do macho foi filmada por 60 minutos e, posteriormente, quantificada.

Grupo experimental 2: fêmea com estímulo nociceptivo na presença de um macho. Os animais foram previamente adaptados ao ambiente experimental. Inicialmente, o macho foi colocado em gaiola sem maravalha por 30 minutos, a fim de adaptá-lo ao ambiente experimental e permitir que ele deixasse seu odor pela urina e fezes. Imediatamente após a retirada do macho, foi colocado na mesma caixa à fêmea que ali permaneceu também por 30 minutos. Este procedimento foi repetido duas vezes ao dia (manhã e tarde) por três dias consecutivos. Assim, as fêmeas mantiveram contato exclusivamente olfatório com os respectivos machos. No $4^{\mathrm{o}}$ dia, o mesmo procedimento foi repetido, iniciando com a colocação do macho em gaiola sem maravalha por $30 \mathrm{~min}$. Após este período, o macho permaneceu na gaiola recebendo à fêmea previamente adaptada ao seu odor. Entretanto, antes de ser colocada na gaiola com o macho, à fêmea recebeu o estímulo nociceptivo pela injeção subcutânea no dorso da pata esquerda de $40 \mu \mathrm{l}$ de formalina 5\%. A resposta nocifensiva da fêmea foi filmada por 60 minutos e, posteriormente, quantificada.

Grupo experimental 3: grupo-controle, macho e fêmea com estímulo nociceptivo. Camundongo fêmea e macho foram adaptados duas vezes ao dia (manhã e tarde) por três dias consecutivos, ambos desprovidos de qualquer contato com coespecíficos. Dessa forma, ao invés de terem sido submetidos a presença de um coespecífico do gênero oposto, no dia do experimento vivenciaram a dor isoladamente. No qual receberam injeção de formalina $5 \%$, aplicada na pata esquerda. A resposta nocifensiva foi filmada por 60 minutos e, posteriormente, quantificada.

Citologia Vaginal: Para controle de influência hormonal sobre comportamentos nocifensivos, foi determinado neste paradigma, o ciclo estral de cada fêmea. Foram realizadas avaliações microscópicas, nas quais se averiguou os tipos celulares presentes no esfregaço vaginal. As análises basearam-se em quatro estágios do ciclo estral, proestro, estro, metaestro e diestro. Ao se avaliar a citologia vaginal considerou-se, a ausência, a presença e a proporção da celularidade existente, assim como densidade e disposição das células (Cora et al., 2015). O lavado vaginal foi realizado mediante auxílio de uma pipeta, sendo possível conter aproximadamente $0,3 \mathrm{ml}$ de solução salina $0,9 \%$, que Injetada e prontamente aspirada, foi sobreposta em uma lâmina para visualização no microscópio óptico. As coletas se deram entre o término da filmagem e o início da perfusão transcardíaca em paraformoldeído. À citologia 
vaginal de cada fêmea foi correlacionada às repostas comportamentais, tanto no grupo em que o macho recebeu formalina na presença de uma fêmea, quanto no grupo em que à fêmea recebeu formalina na presença de um macho.

\subsubsection{Paradigma 2: influência da prole sobre a manifestação de dor}

Experimento 4: fêmea (mãe) com dor na presença dos filhotes. Machos e fêmeas foram colocados aos pares em gaiolas individuais para acasalamento. Após a parição, quando os filhotes alcançaram o $7^{\circ}$ dia de vida, à mãe junto a seus filhotes, foi adaptada em gaiola sem maravalha, por 60 minutos duas vezes ao dia (manhã e tarde) por três dias consecutivos. No $4^{\circ}$ dia, quatro a cinco filhotes foram transferidos para a gaiola de experimentação, sem maravalha, e consecutivamente, à mãe recebeu o estímulo nociceptivo, mediante injeção de $40 \mu \mathrm{l}$ de formalina subcutânea $5 \%$ na pata esquerda. Após à injeção, à mãe foi colocada junto a seus filhotes na gaiola. À resposta nocifensiva da fêmea mãe foi filmada por 60 minutos e, posteriormente, quantificada.

Experimento 5: macho (pai) com dor na presença dos filhotes. Machos e fêmeas foram colocados aos pares em gaiolas individuais para acasalamento. Após a parição, quando os filhotes alcançaram o $7^{\circ}$ dia de vida, o pai e seus filhotes foram adaptados em gaiola sem maravalha, por 60 minutos duas vezes ao dia (manhã e tarde) por três dias consecutivos. No $4^{\circ}$ dia, quatro a cinco filhotes foram transferidos para a gaiola de experimentação, sem maravalha, e imediatamente após, o pai recebeu o estímulo nociceptivo, mediante injeção de $40 \mu \mathrm{l}$ de formalina subcutânea $5 \%$ na pata esquerda. Posteriormente a injeção, o pai foi colocado junto a seus filhotes na gaiola. À resposta nocifensiva do macho foi filmada por 60 minutos e, mais tarde quantificada.

3.2.3 Paradigma 4: influência do parentesco de irmãos sobre a manifestação de dor

Experimento 10: macho com estímulo nociceptivo na presença de um irmão. Posteriormente efetivado o desmame, no $21^{\circ}$ dia, os machos seguiram para uma gaiola exclusiva, possibilitando assim o vínculo social entre estes animais. Para abolir a influência hierárquica, o macho dominante foi retirado do experimento. Subsequentemente, os machos 
foram selecionados em duplas e, por conseguinte, colocados em gaiola sem maravalha por 60 min, com intenção de adaptá-los ao ambiente experimental e permitir que ambos deixassem seu odor pela urina e fezes. Este procedimento foi repetido duas vezes ao dia (manhã e tarde) por três dias consecutivos. Assim, os irmãos mantiveram contato direto. No $4^{\circ}$ dia, o mesmo procedimento foi repetido, iniciando com a colocação dos dois animais em gaiola sem maravalha por 30 minutos. Os animais foram previamente adaptados ao ambiente experimental. Dentre os dois machos, um recebeu o estímulo nociceptivo mediante injeção subcutânea no dorso da pata esquerda de $40 \mu \mathrm{l}$ de formalina 5\%. À resposta nocifensiva do irmão foi filmada por 60 minutos e, mais tarde, quantificada.

Experimento 11: fêmea com estímulo nociceptivo na presença de sua irmã. Da mesma maneira descrita no paradigma 10, procedeu-se o desmame das fêmeas, e retirada à fêmea dominante, estas foram previamente selecionadas em duplas e de forma idem ao paradigma 10, foram adaptadas ao ambiente experimental, permitindo o contato direto entre fêmeas irmãs. No $4^{\circ}$ dia, o mesmo procedimento foi repetido, iniciando com a colocação das duas fêmeas em gaiola sem maravalha por 30 minutos. Os animais foram previamente adaptados ao ambiente experimental. Dentre as duas fêmeas uma, recebeu o estímulo nociceptivo pela injeção subcutânea no dorso da pata esquerda de $40 \mu \mathrm{l}$ de formalina $5 \%$. À resposta nocifensiva da fêmea foi filmada por 60 minutos e, mais tarde, quantificada.

\subsubsection{Teste do tubo}

O protocolo empregue a fim de avaliar a hierarquia social foi constituído de três etapas básicas:

a) habituação: Meio pelo qual se torna possível a redução, tanto do estresse, quanto da ansiedade provocados pela manipulação. Dessa forma, os camundongos foram apresentados ao tubo, que se encontrara fixado à base da gaiola de alojamento. O tempo total de livre exploração ao tubo para adaptação e aprendizagem foi de seis horas distribuídas em dois turnos (uma hora pela manhã e uma hora pela tarde) por três dias consecutivos. A partir da primeira habituação, os camundongos foram estimulados a passar pelo tubo, estando dessa forma, nas últimas habituações, aptos ao teste. O manuseio na habituação, teve por finalidade contribuir para que o camundongo se acostumasse ao examinador, diminuindo dessa forma, o fator de estresse (Fan et al., 2019). 
b) teste: neste, os camundongos foram testados em grupos constituídos de três a seis animais. O camundongo com maior número de vitórias foi tido por dominante do grupo, de forma que em um rodízio de testes sucessivos, o animal derrotado era retornado à gaiola, permanecendo o vencedor, até que se encontrou aquele que venceu todos do grupo, sendo assim designado dominante.

c) gravação por câmera de vídeo: Por intermédio de gravação com câmera de vídeo, registrou-se o comportamento de dominância de cada grupo, permitindo posterior avaliação (offline) do tempo despendido pelo animal dominante a expulsar um a um seus colegas de grupo, demarcado numa prospecção temporal prévia e consecutiva ao estímulo prónociceptivo.

\subsubsection{Modelo nociceptivo inferido ao teste do tubo}

Após identificado o animal dominante, procedeu-se com a gravacão do primeiro teste, no qual o camundongo dominante, desprovido de qualquer estímulo nóxico, expulsara de um a um seus subordinados. Por conseguinte, o mesmo fora submetido ao estímulo prónociceptivo, injeção de Completo Adjuvante de Freund (CFA).

\subsubsection{Injeção de CFA}

Procedeu-se com injeção dorso-plantar de $40 \mu \mathrm{l}$ de CFA, sendo na sequência, realizadas novas gravações, nos seguintes tempos, seis horas, 24 horas e sete dias pós estimulo pró-nociceptivo. A Injeção de CFA, é um modelo que propicia a dor de origem inflamatória. O Completo Adjuvante de Freund (CFA) constitui-se de uma emulsão preparada à base de fragmentos de Mycobacterium tuberculosis, desenvolvida originalmente por Jules Freund, em meados de 1940, e é potencialmente capaz de conceber um forte e persistente processo inflamatório (FREUND, 1947). Desse modo, produzindo inflamação local, seguida dos cinco sinais cardinais da inflamação, sendo estes dor, calor, rubor, tumor e perda da função. A injeção de CFA causa ainda, edema e hiperalgesia (Stein et al., 1988; Fehrenbacher et al., 2012). 


\subsubsection{Avaliação das respostas nocifensivas}

Foram avaliadas duas respostas nocifencivas, número de sacudidas e tempo de lambida do membro afetado. A quantificação do comportamento de sacudida, se deu por meio do auxílio de um contador manual. Sendo considerado o período de uma hora, dividida em dois tempos, fase 1(10 min iniciais) e fase 2 (50 min remanescentes). De modo análogo, fase 1 e fase I2, o tempo de lambida foi cronometrado mediante auxílio de cronometro digital. As análises dos vídeos foram realizadas em offline. Finalizada à gravação, o animal foi

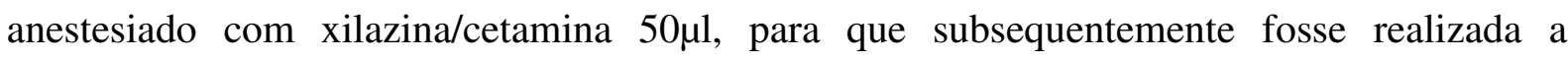
perfusão transcardíaca com paraformoldeído, $70 \mathrm{ml}$ da solução durante 15 minutos de perfusão.

\subsection{Análise estatística}

Os dados do presente estudo foram apresentados com as médias \pm erro padrão da média (SEM). Os quais foram analisados por ANOVA de uma via. O valor absoluto dos comportamentos foi plotado no gráfico em pontos dispersos. Em cada caso foi considerado um nível de significância de $p<0,05$. Análises estatísticas foram realizadas com auxílio do software Statistica 7. 


\section{RESULTADOS}

Considerando o isolamento um contexto social, camundongo macho e camundongo fêmea foram submetidos a dor isolados da presença de qualquer coespecífico. No teste de formalina, quando comparado o macho que vivenciou a dor isolado, com à fêmea submetida a dor em isolamento, ambos não apresentaram diferenças significativas quanto a expressão de comportamentos nocifensivos. Tanto no número de sacudidas (Fig. 1), quanto no tempo de lambida (Fig. 2).

\section{Grupo controle}

Figura 1 -Fêmea* isolada $\mathbf{x}$ macho* isolado (número de sacudidas)

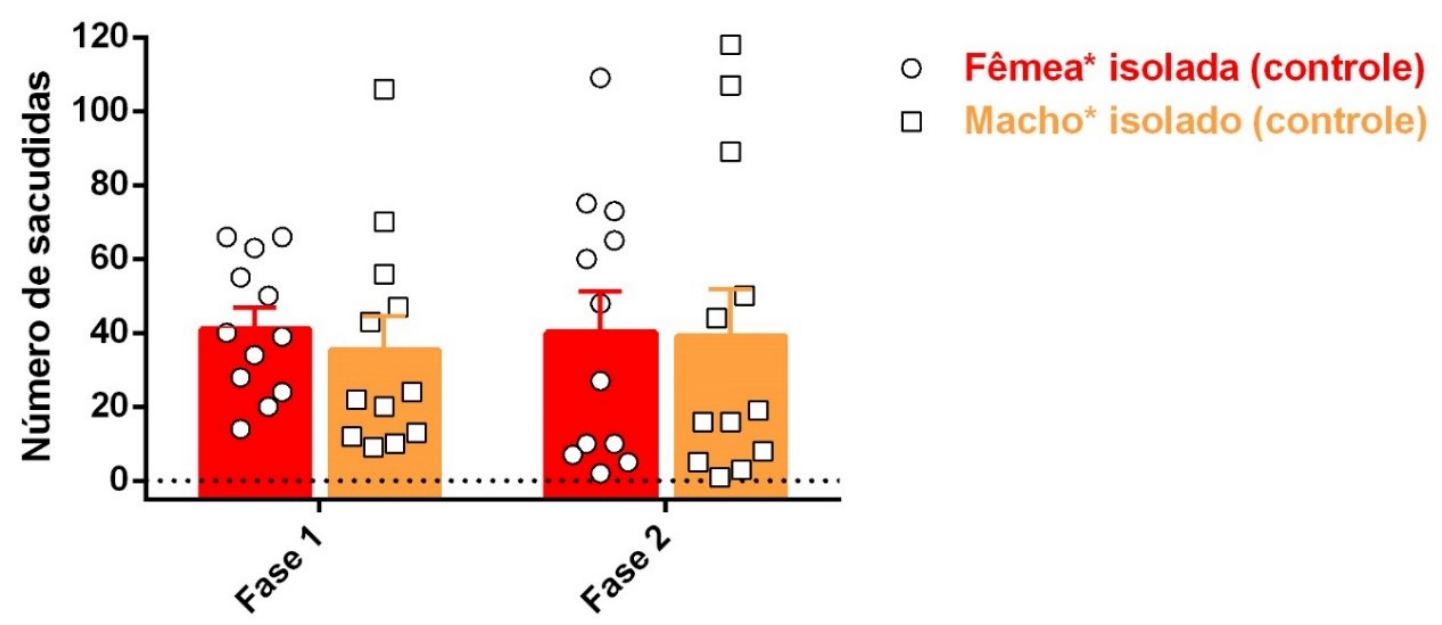


Figura 2 - Fêmea* isolada $x$ macho* isolado (tempo de lambida)

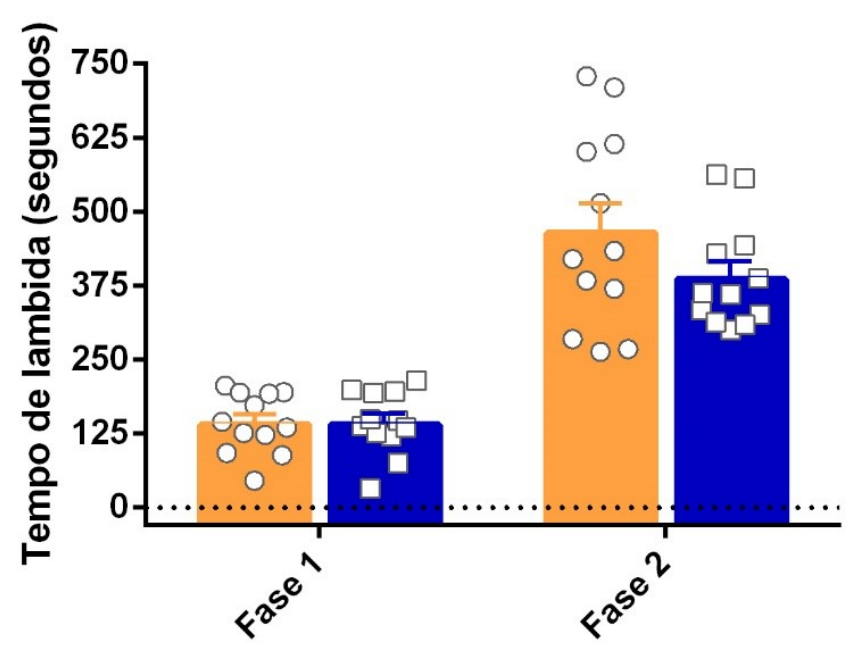

- Macho* isolado (controle)

$\square$ Fêmea* isolada (controle)

Fonte: LEITE, F. R. ${ }^{\mathbf{1 , 2}}$, CARVALHO, A. M. ${ }^{\mathbf{1 , 2}}$, ZANON, S²., LUCAS, G. ${ }^{\mathbf{1}, \mathbf{2}}$ (2019).

As Figuras 1 e 2 - equiparam a expressão dos comportamentos nocifensivos entre o macho e à fêmea que experimentou dor isoladamente, os quais não mostraram diferenças significativas. Asterisco no texto representa o tratamento (teste de formalina); barras demonstram a média \pm erro padrão. Número de sacudida, fase $1 p=$ 0,58 , fase $2 p=0,93$ (1). Tempo de lambida, fase $1 p=0,97$, fase $2 p=0,17$ (2). Análise de variância de uma via ( $\mathrm{n}=12$ por grupo). Símbolos (círculo e quadrado) representam os valores absolutos de cada animal.

Com o objetivo de avaliar a relevância da presença do coespecífico familiar sob a interpretação da dor, camundongo fêmea e camundongo macho foram submetidos ao estímulo nóxico em companhia de um irmão do mesmo gênero. No número de sacudidas, o macho que vivenciou a dor junto a um irmão, não diferiu daquele a experimentou isoladamente (Fig. 3). Contrariamente, na presença de um irmão, o macho demonstrou significativamente menor tempo de lambida em relação ao macho do contexto de isolamento (Fig. 4). 
Semelhantemente, no número de sacudidas, à Fêmea não apresentou diferença, quando em presença de uma irmã (Fig. 5). Mas na fase um do tempo de lambida, se observou diferença significativa entre à fêmea com dor na presença de uma irmã e à fêmea com dor isolada (Fig. $6)$.

\section{Contexto de irmãos}

Figura 3 - Macho* isolado x macho* + irmão (número de sacudidas).

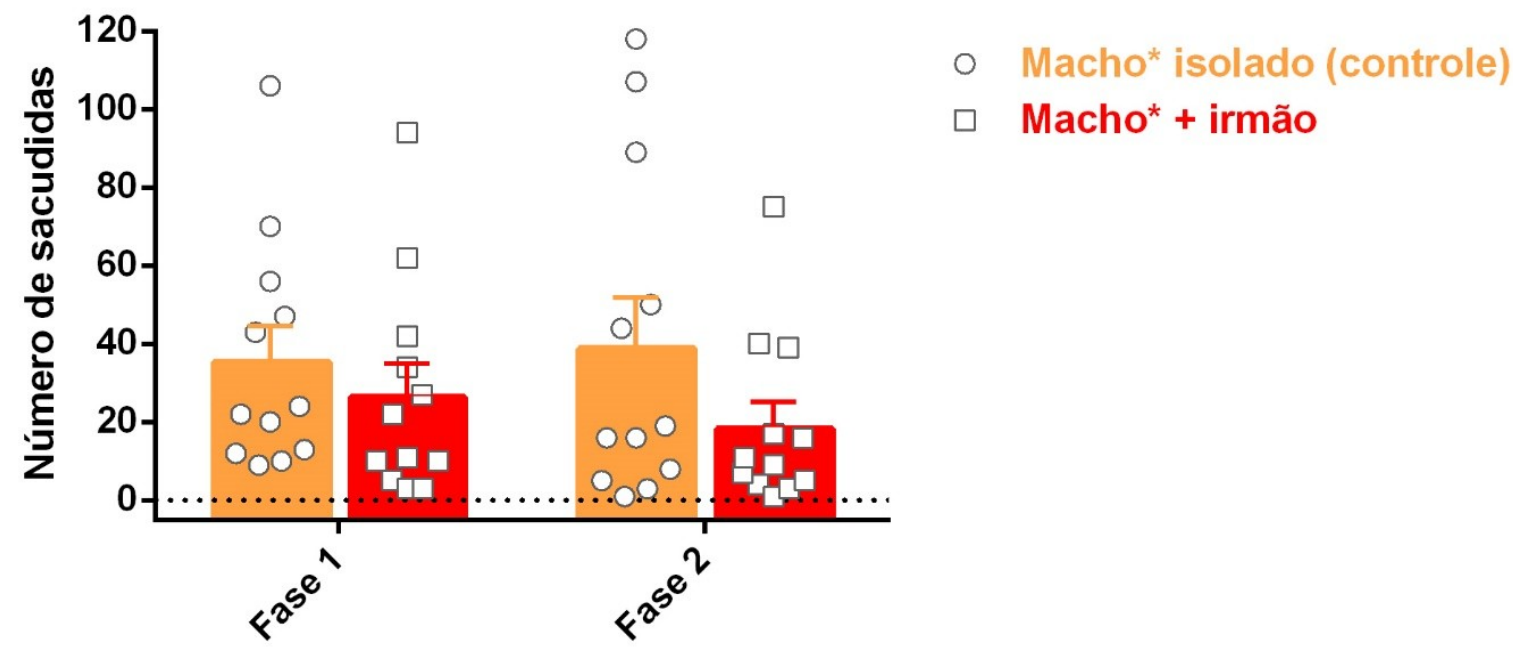

Figura 4 - Macho* isolado x macho* + irmão (tempo de lambida). 


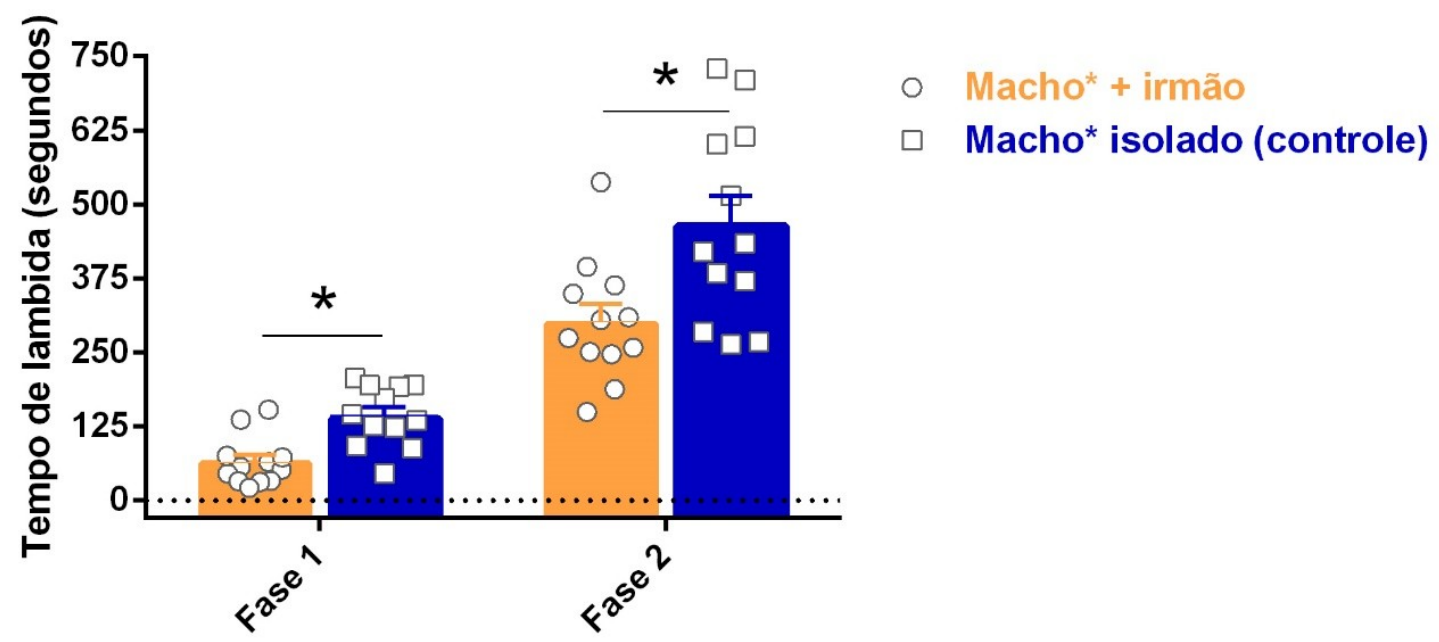

Figura 5 - Fêmea* isolada x Fêmea* + irmã (número de sacudidas)

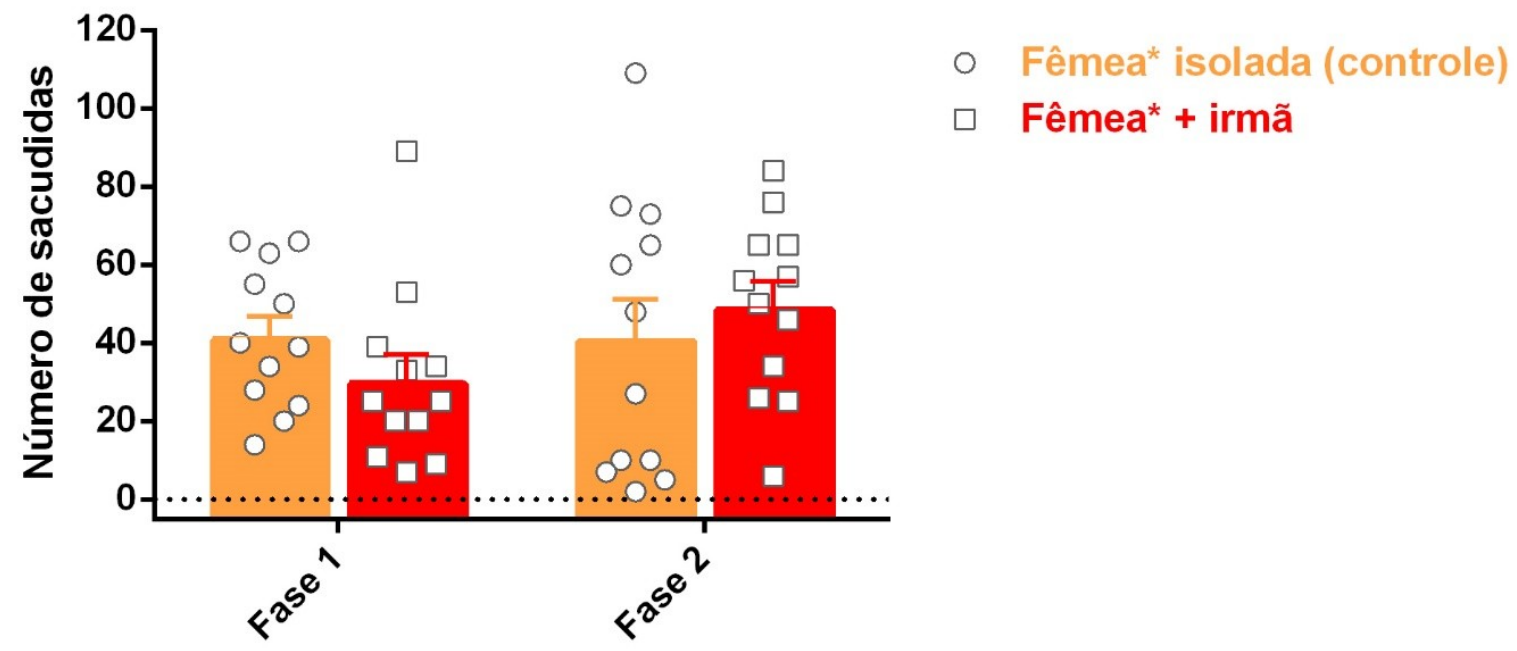

Figura 6 - Fêmea* isolada x Fêmea* + irmã (tempo de lambida) 


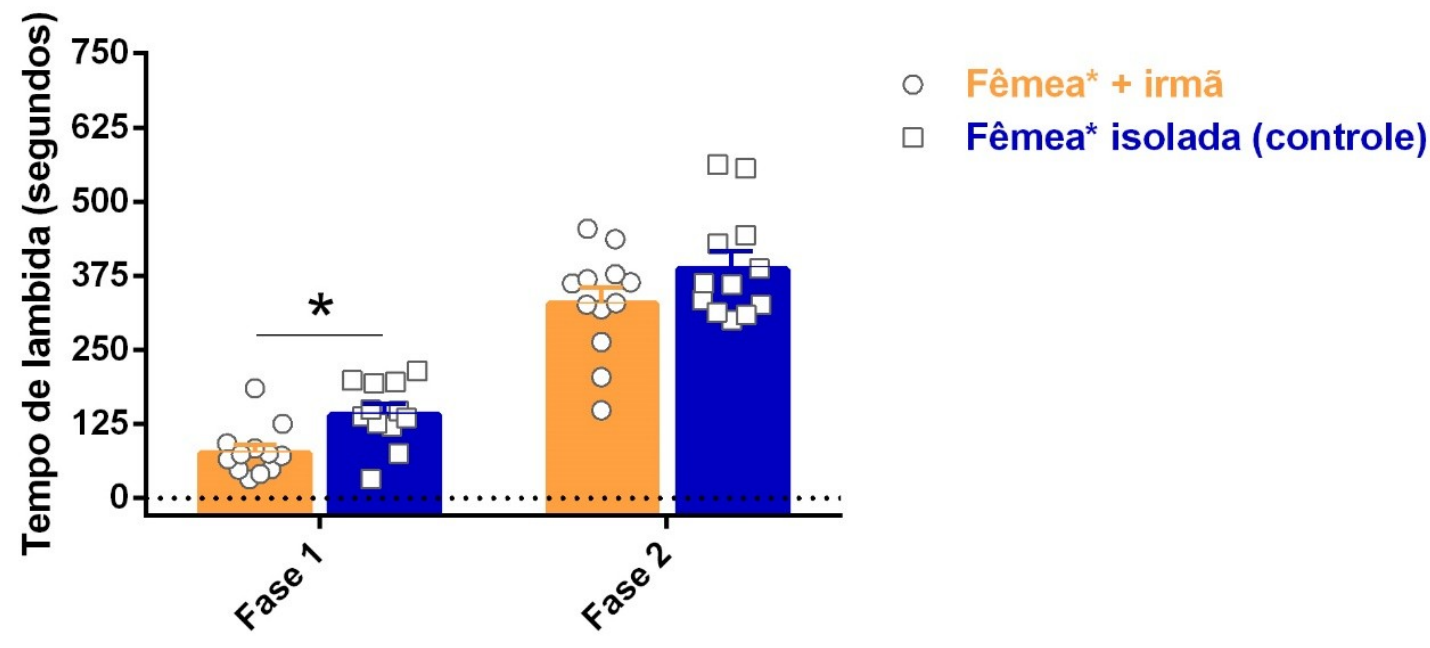

Fonte: LEITE, F. R., ${ }^{\mathbf{1} 2}$, CARVALHO, A. M. ${ }^{\mathbf{1 , 2}}$, ZANON, S²., LUCAS, G., ${ }^{\mathbf{1 , 2}}$ (2019).

As Figuras 3 a 6 - correlacionam a manifestação dos comportamentos nocifensivos entre macho e fêmea na presença de um irmão(a) com macho e fêmea do contexto de isolamento. No macho, o número de sacudidas não foi influenciado pela presença de um irmão, fase $1 p=0,44$, fase $2 p=0,14$ (3). Porém, no tempo de lambida houve diferença marcante comparado ao macho isolado, fase $1 * p=<0,05$, fase $2 * p=<0,05$ (4). À fêmea em presença de uma irmã não demonstrou diferença relevante no número de sacudidas, fase $1 p=0,19$, fase $2 p=$ 0,50 (5). No entanto, quando se observou o tempo de lambida, à fêmea na presença de uma irmã, comparada à fêmea que vivenciou dor isoladamente, mostrou diferença significativa na fase 1 do teste, fase $1 * p=<0,05$, o que não foi verdade na fase $2 p=0,11$ (6). Asterisco no texto representa o tratamento, no gráfico, acima da barra, representa a significância. Análise de variância de uma via (n= 12 por grupo). Símbolos (círculo e quadrado) representam os valores absolutos de cada animal.

No intuito de avaliar a interpretação da dor na presença de um coespecífico de gênero oposto, camundongo fêmea foi submetida a dor junto a um macho e o camundongo macho junto a uma fêmea. Quando comparado ao macho que experimentou a dor isoladamente, observou-se no macho exposto à uma fêmea diferença significativa, tanto no número de sacudidas (Fig. 7), quanto no tempo de lambida (Fig. 8), as quais aconteceram nas duas fases dos comportamentos. Comparada à fêmea do contexto de isolamento, à camundongo fêmea que passou pela dor na presença do macho apresentou diferença na fase 1 do número de sacudidas, porém não na fase 2 (Fig. 9). No tempo de lambida diferença marcante se deu, nas duas fases, porém com maior relevância na fase 1 (Fig. 10). 
Contexto de gênero oposto

Figura 7 - Macho* isolado x macho* + fêmea (número de sacudidas).

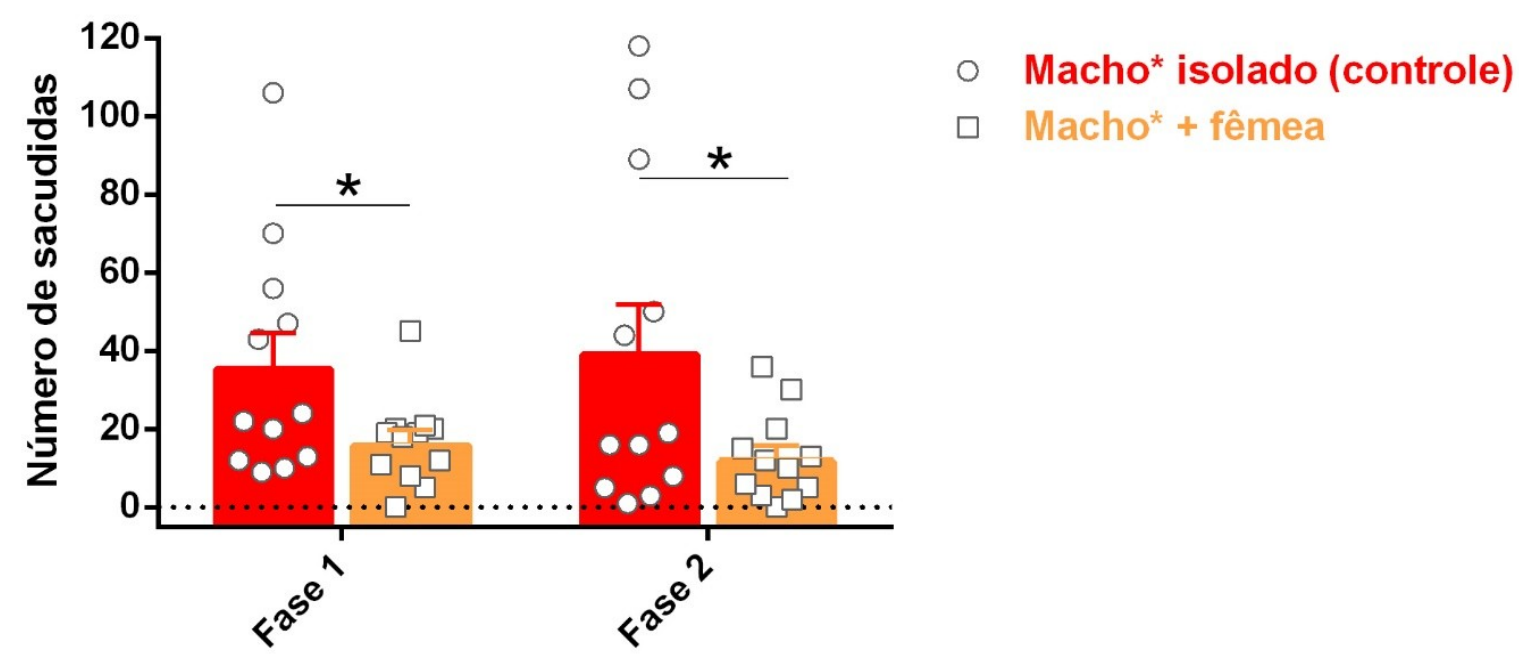

Figura 8 - Macho* isolado x macho* + fêmea (tempo de lambida)

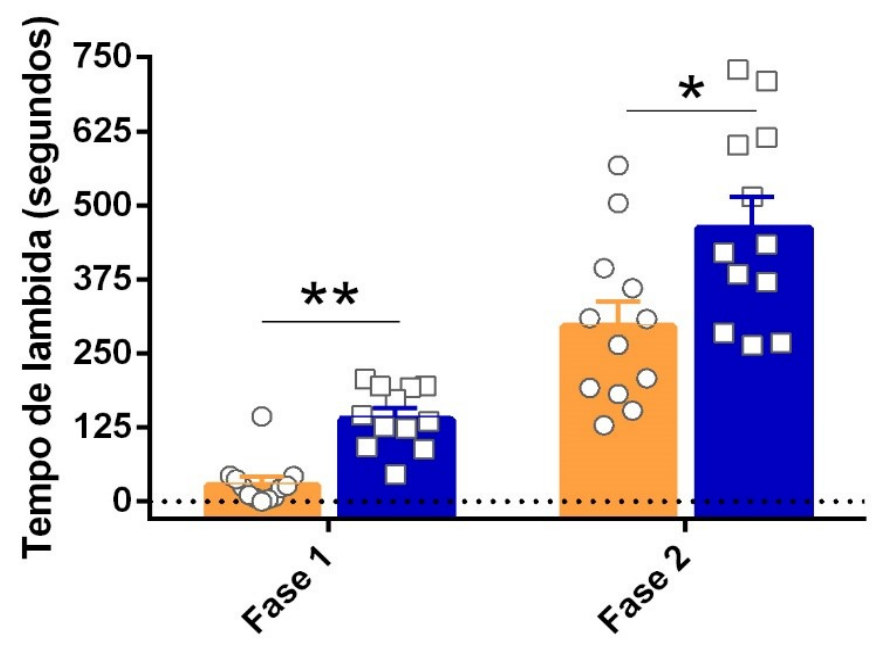

Figura 9 - Fêmea* isolada x fêmea* + macho (número de sacudidas) 


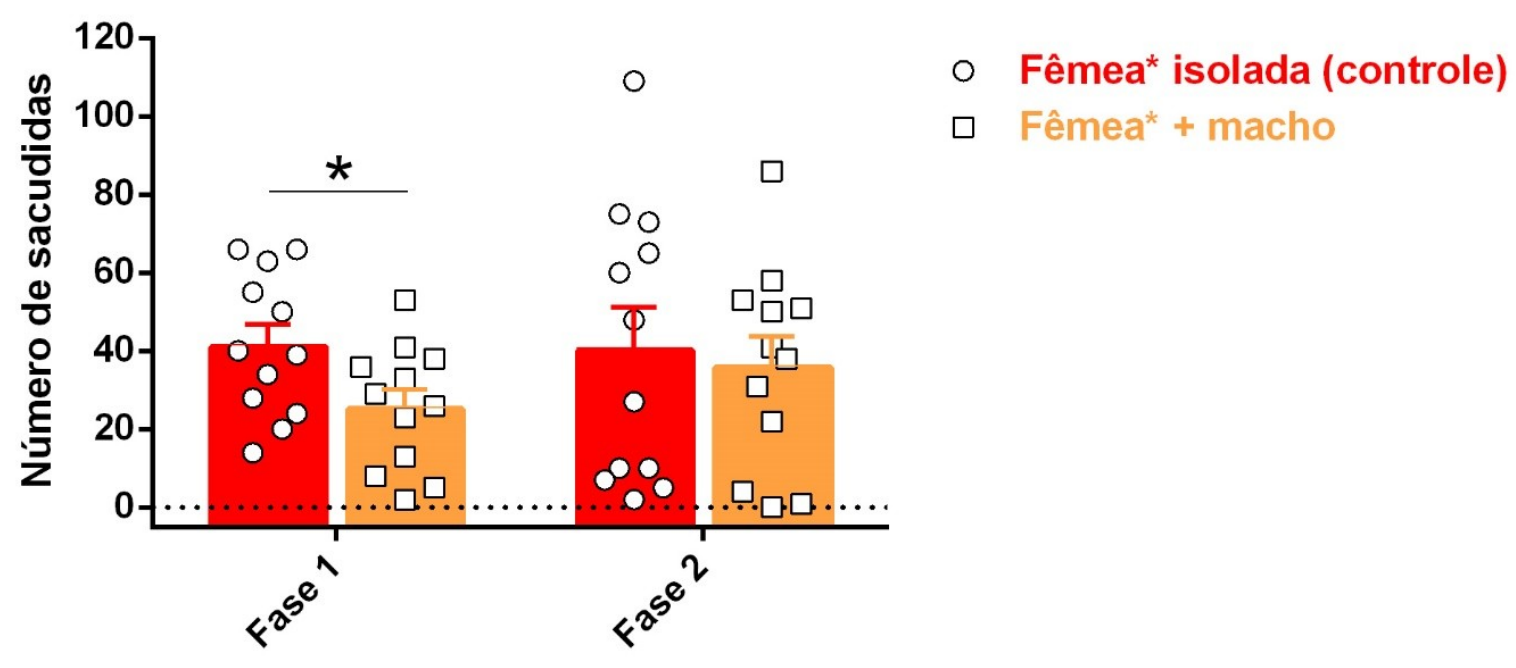

Figura 10 - Fêmea* isolada x fêmea* + macho (tempo de lambida)

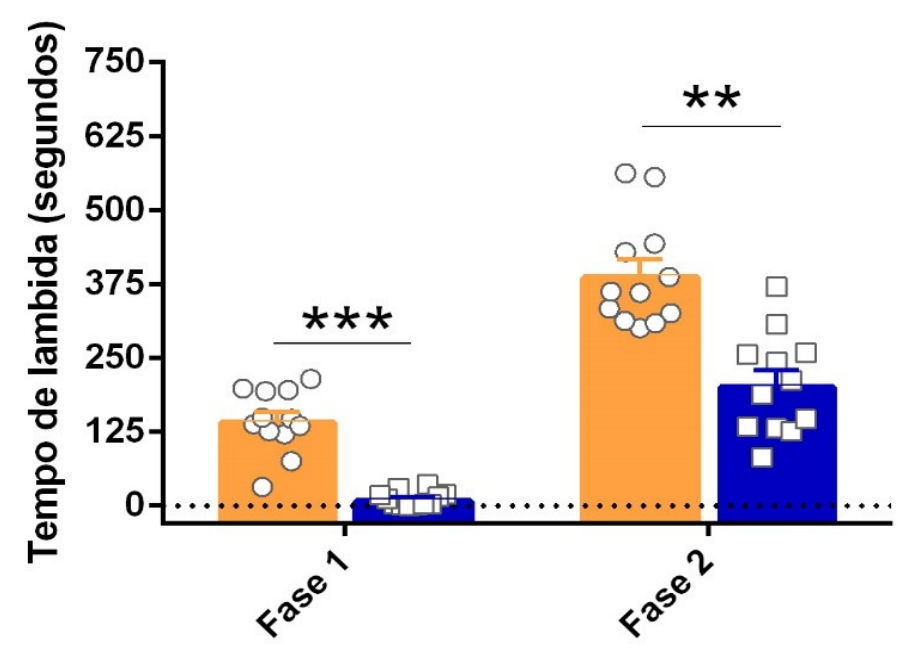

Fonte: LEITE, F. R. ${ }^{1,2}$, CARVALHO, A. M. ${ }^{1,2}$, ZANON, S², LUCAS, G. ${ }^{1,2}$ (2019). 
As Figuras 7 a 10 - mostram a relação entre a presença de gênero oposto e a expressão de comportamentos nocifensivos, na qual diferenças significativas foram constatadas entre o macho que vivenciou a condição de dor na presença de uma fêmea e o macho que passou pela experiência de dor isoladamente. Nesse sentido, em companhia da fêmea, o macho obteve redução em suas respostas nocifensivas, no número de sacudidas, tanto à Fase 1, quanto à fase 2 apresentaram ${ }^{*} p=<0,05$ (7). No tempo de lambida o macho demonstrou diferença nas duas fases do comportamento, fase $1 * * p=<0,005$ e fase $2 * p=<0,05(\mathbf{8})$. À fêmea que experimentou a dor junto ao macho, apresentou diferença significativa quando comparada à fêmea que foi submetida a dor isoladamente. No número de sacudidas a diferença se deu na primeira fase do teste, fase $1 * p=<0,05$ (9). No tempo de lambida, à fêmea caracterizou-se de expressiva redução, tanto na fase 1, quanto na fase 2 do teste, fase $1 * * * p=<0,0005$, fase $2 * * p=<0,005$ (10). Asterisco no texto representa o tratamento, no gráfico, acima da barra representa a significância. Cada barra representa à média \pm erro padrão, análise de variância de uma via (n= 12 por grupo). Símbolos (círculo e quadrado) representam os valores absolutos de cada animal.

Com objetivo de averiguar possível influência das fases estrais na manifestação da resposta nocifensiva no macho submetido a dor na presença da fêmea e outrora na fêmea passando pela dor junto ao macho, correlações não foram observada entre o número de sacudidas (Fig. 11), bem como entre o tempo de lambida (Fig. 12) da fêmea com dor em companhia do macho. Semelhantemente, no macho em condição de dor na presença da fêmea, não se observou relação significativa entre a manifestação de dor e ciclo estral. Tanto no número de sacudidas (Fig. 13), quanto no tempo de lambida (Fig. 14).

\author{
Relação ciclo estral e comportamento nocifensivo
}

Figura 11 - Fêmea* + macho: ciclo estral x número de sacudidas 


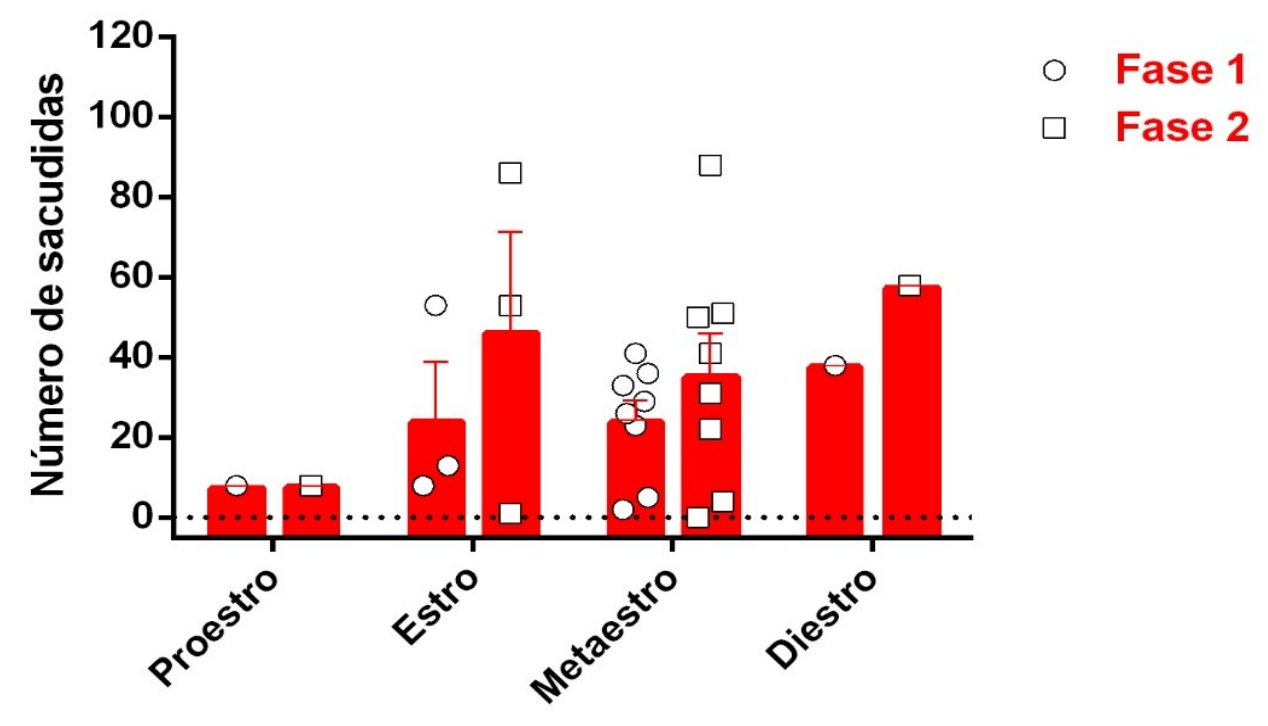

Figura 12 - Fêmea* + macho: ciclo estral $x$ tempo de lambida

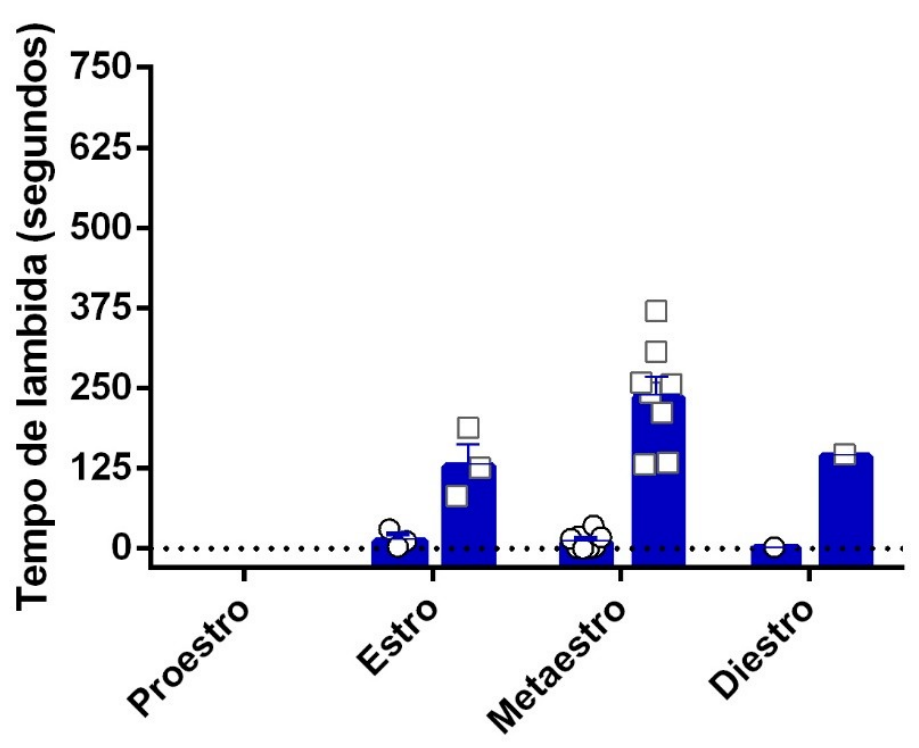

- Fase 1

Fase 2 
Figura 13 - Macho* + fêmea: ciclo estral x número de sacudidas

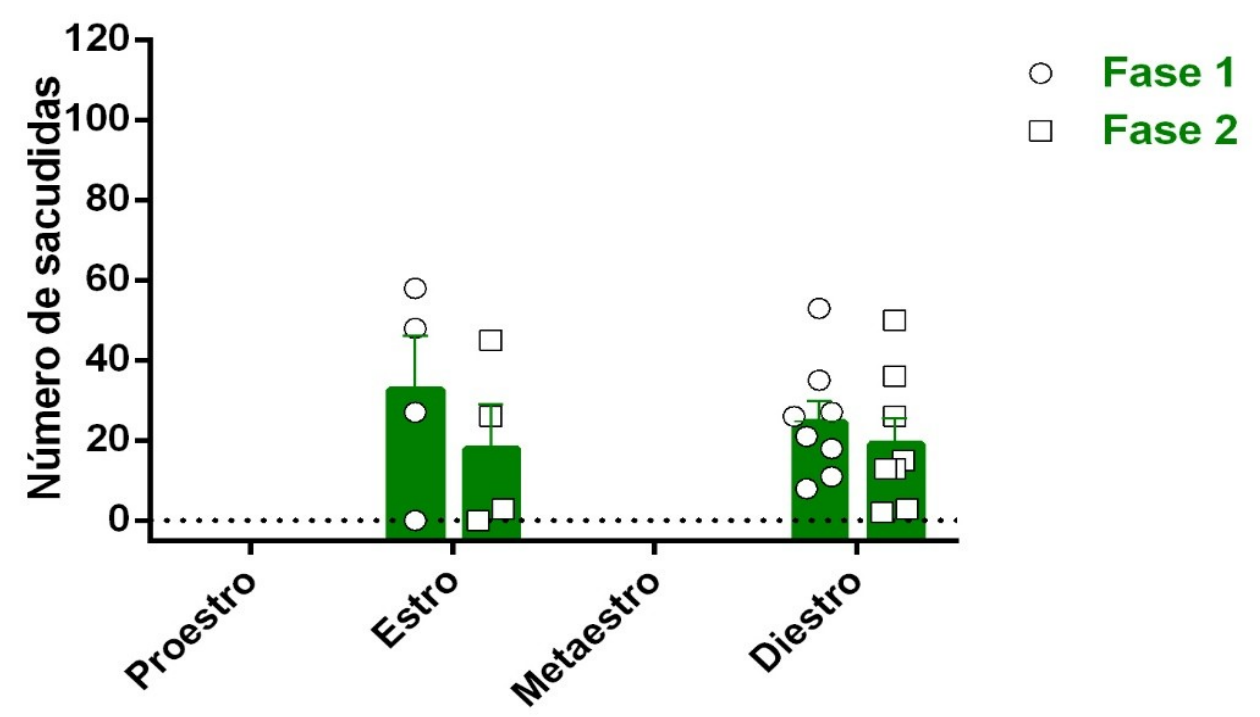

Figura 14 - Macho* + fêmea: ciclo estral x tempo de lambida

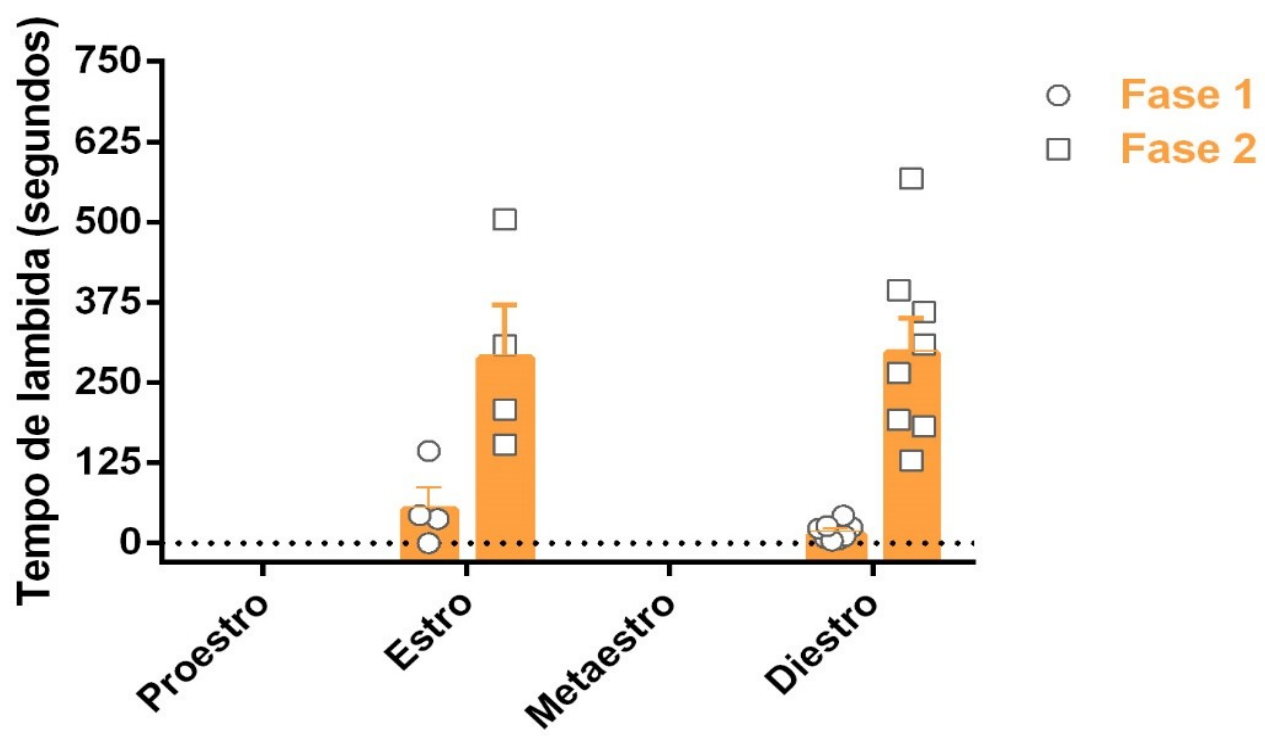

Fonte: LEITE, F. R..,2, CARVALHO, A. M.1,2 ZANON, S²., LUCAS, G. ${ }^{1,2}$ (2019).

As Figuras 11 a 14 - trazem a relação, ciclo estral e respostas nocifensivas, na qual diferença significativa entre ciclo estral e comportamento nocifensivo não foi encontrada na fêmea submetida a estimulação dolorosa em presença do macho. Número de sacudidas, fase $1 p=0,99$; fase $2 p=0,86$ (11). Tempo de lambida, fase $1 p=$ 0,69; fase $2 p=0,13$ (12). Do mesmo modo, diferença relevante no comportamento do macho submetido a condição dolorosa em presença da fêmea que o acompanhava, não foi verificada. Número de sacudidas, fase 1 $p=0,47$; fase $2 p=0,91$ (13). Tempo de lambida, fase $1 p=0,11$; fase $2 p=0,94$ (14). Estes dados, sugerem que o ciclo estral não exerceu influência na resposta comportamental do paradigma de gênero oposto. Cada barra representa à média \pm erro padrão, análise de variância de uma via $(\mathrm{n}=1-8$ por grupo). 
Em razão de o cuidado parental ser um atributo essencial dos animais para contiguidade das espécies, foi investigado como a presença da prole pode interferir na resposta nocifensiva do macho pai e da fêmea mãe. No número de sacudidas não houve diferença significativa entre o macho que experimentou dor no contexto de isolamento e o macho que passou pela dor na presença de sua prole (Fig. 15). No tempo de lambida se observou diferença somente na fase um do teste (Fig. 16). Diferentemente do macho, a presença da prole foi expressivamente relevante para fêmea, a qual expressou infimamente os comportamentos nocifensivos, quando comparada à fêmea que passou pela dor isoladamente, assim, tanto o número de sacudidas (Fig. 17), quanto o tempo de lambida (Fig. 18) na fêmea mãe, foram significativamente inferiores.

\section{Contexto parental}

Figura 15 - Macho* isolado x pai* + prole (número de sacudidas)

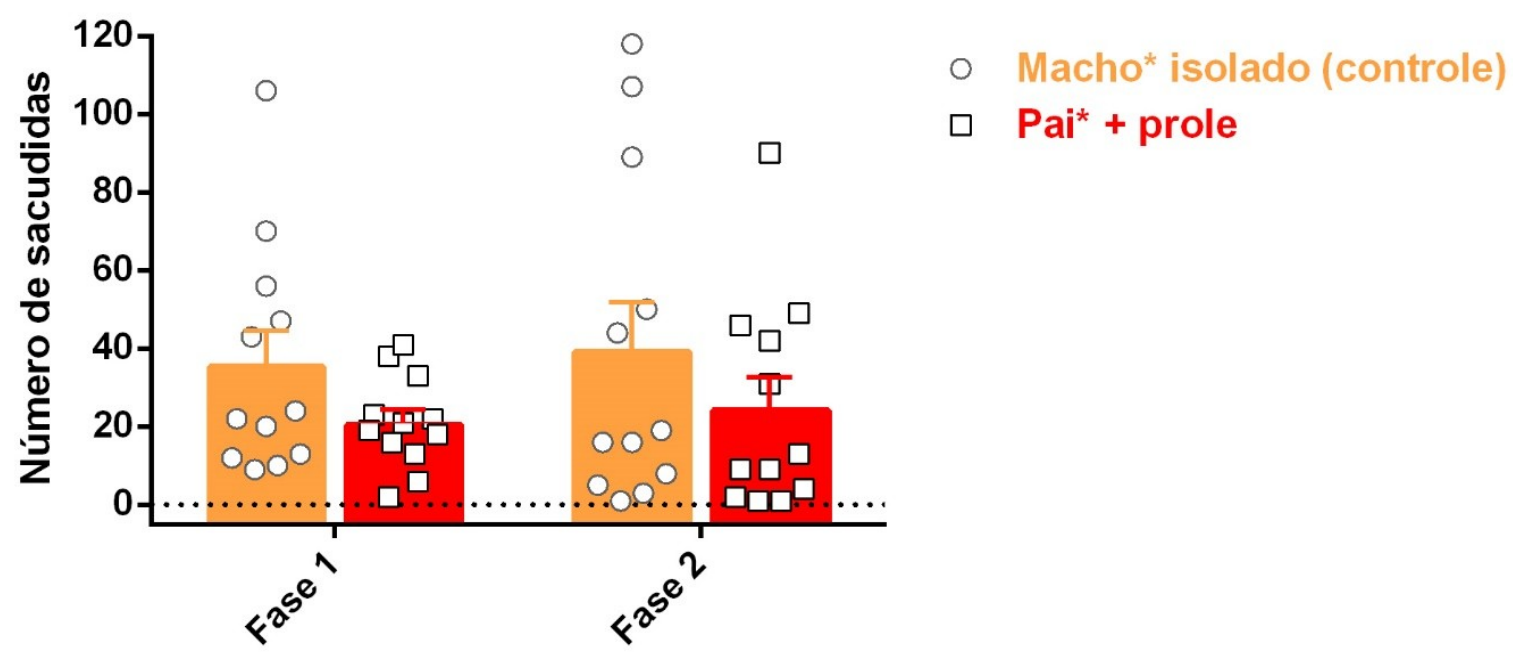


Figura 16 - Macho* isolado x pai* + prole (tempo de lambida)

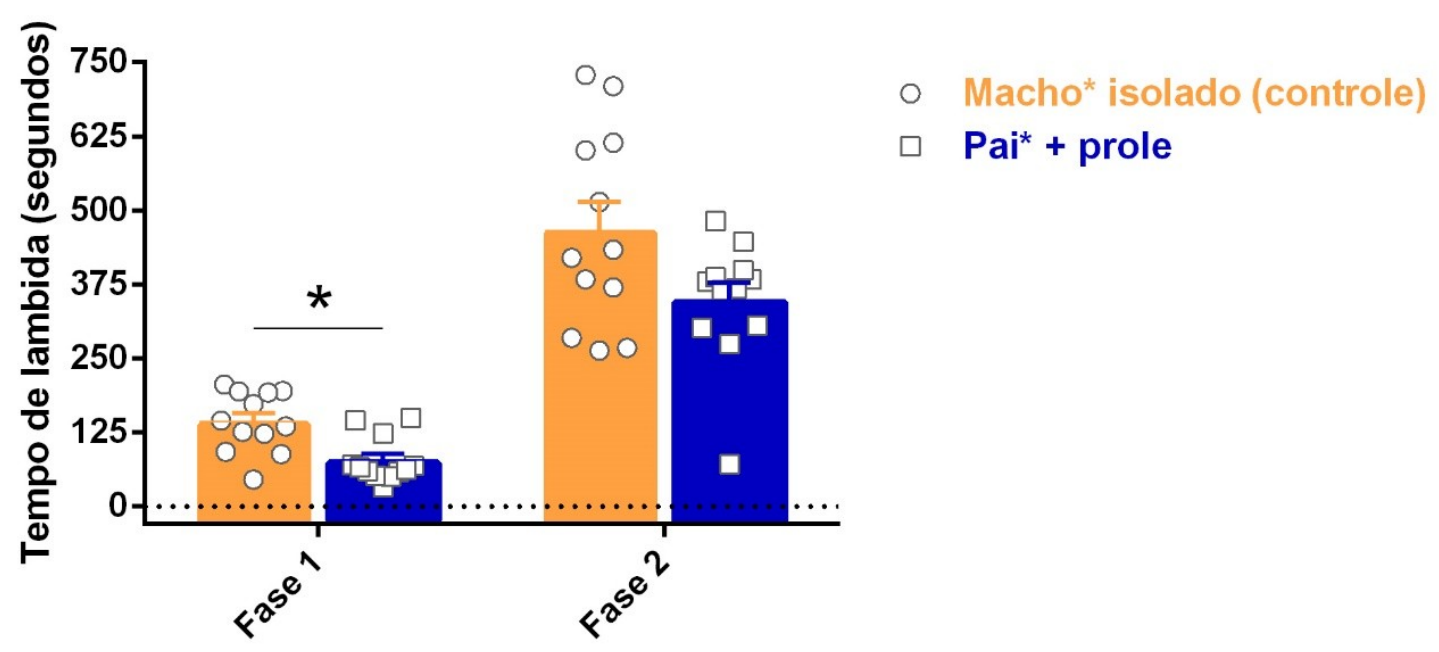

Figura 17 - Fêmea* isolada x mãe* + prole (número de sacudidas)

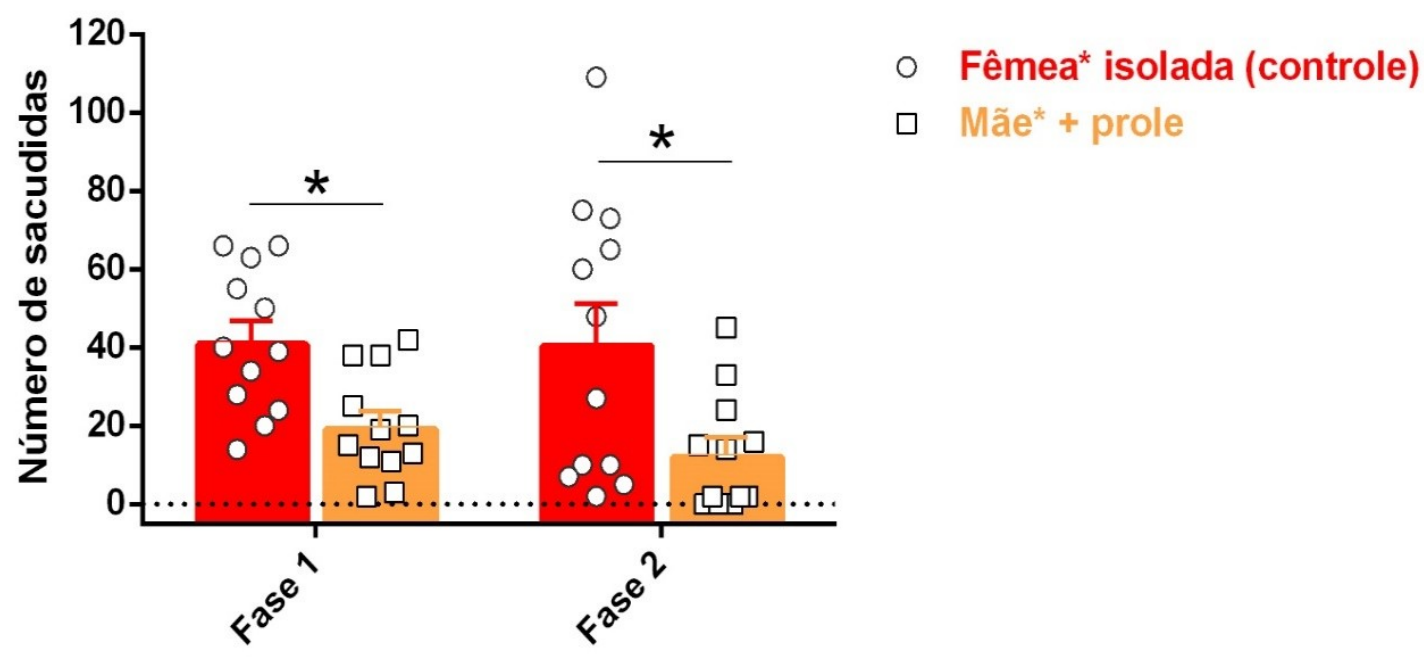


Figura 18 - Fêmea* isolada x mãe* + prole (tempo de lambida)

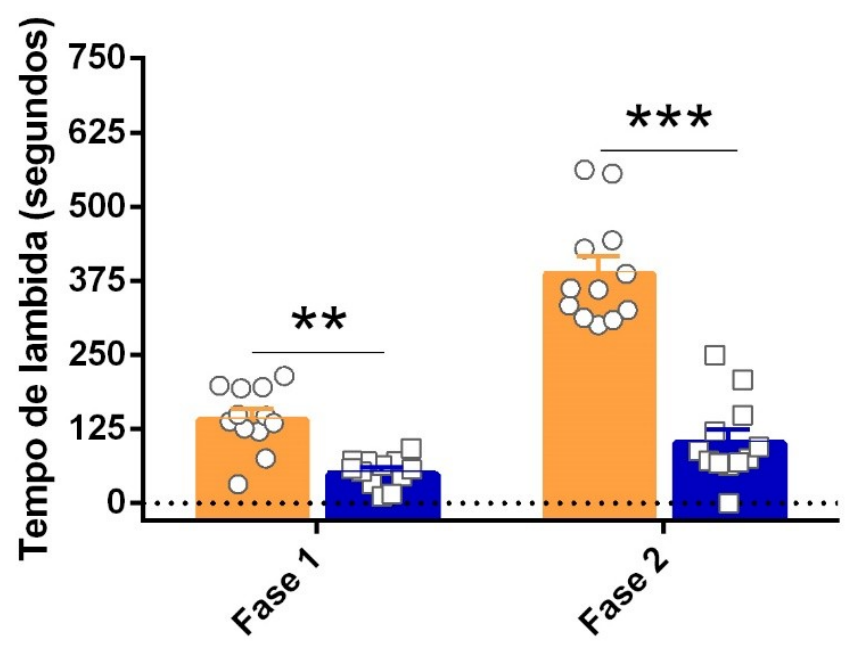

- Fêmea* isolada (controle)

․ Mãe* prole

Fonte: LEITE, F. R. ${ }^{1,2}$, CARVALHO, A. M. ${ }^{1,2}$, ZANON, S²., LUCAS, G. ${ }^{1,2}$ (2019).

As Figuras 15 a 18 - apontam uma disparidade entre os comportamentos nocifencivos do macho pai e da fêmea mãe, ao experimentar a condição de dor na presença da prole, quando comparados com o macho e a fêmea do contexto de isolamento. No número de sacudidas, não foi observado diferença entre o macho submetido a dor isoladamente e o macho que vivenciou dor na presença da prole. Fase $1 p=0,11$; fase $2 p=0,31$ (15). No tempo de lambida, foi observado diferença relevante apenas na fase $1, * p=<0,05$, fase $2 p=0,05(16)$. No entanto, à fêmea mãe manifestou de maneira ínfima suas respostas nocifensivas, as quais se caracterizaram por diferença marcante no número de sacudidas, assim foi verificado diferença entre à fêmea que passou pela dor na presença da prole e à fêmea submetida a dor isoladamente, Fase $1 * p=<0,05$; fase $2 * p=<0,05$ (17). Mais proeminentemente o tempo de lambida, fase $1 * * p=<0,005$; fase $2 * * * \mathrm{p}=<0,0005$ (18). Asterisco no texto representa o tratamento, no gráfico, acima da barra, representa a significância. Cada barra representa à média \pm erro padrão, análise de variância de uma via ( $\mathrm{n}=12$ por grupo). Símbolos (círculo e quadrado) representam os valores absolutos de cada animal.

À interferência da dor foi testada no contexto da hierarquia social de dominância, neste o macho e à fêmea dominante foi testado antes (basal) e após ser submetido a dor, e posteriormente avaliados quanto ao tempo gasto para expulsar do tubo os subordinados do grupo, nas diferentes fases da dor persistente, seis horas, 24 horas (pico da inflamação) e sete dias pós estímulo doloroso. Tanto o macho, quanto à fêmea manteve a uniformidade no tempo despendido para expulsar seus subordinados após estimulação nociceptiva (Fig. 19 e 20). 
Relação hierarquia social e dor

Figura 19 - Macho* dominante x subordinados (tempo de expulsão)

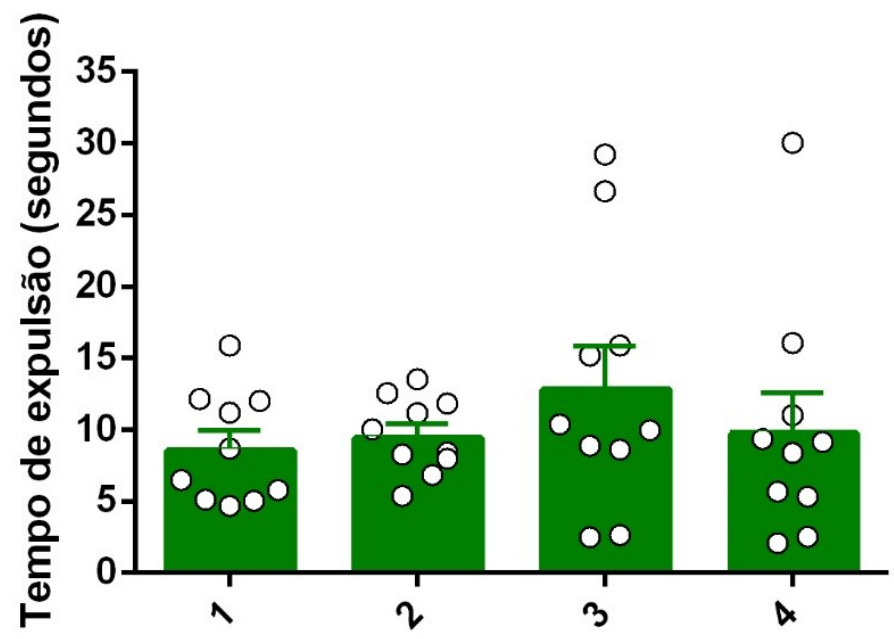

Figura 20 - Fêmea* dominante x subordinadas (tempo de expulsão)

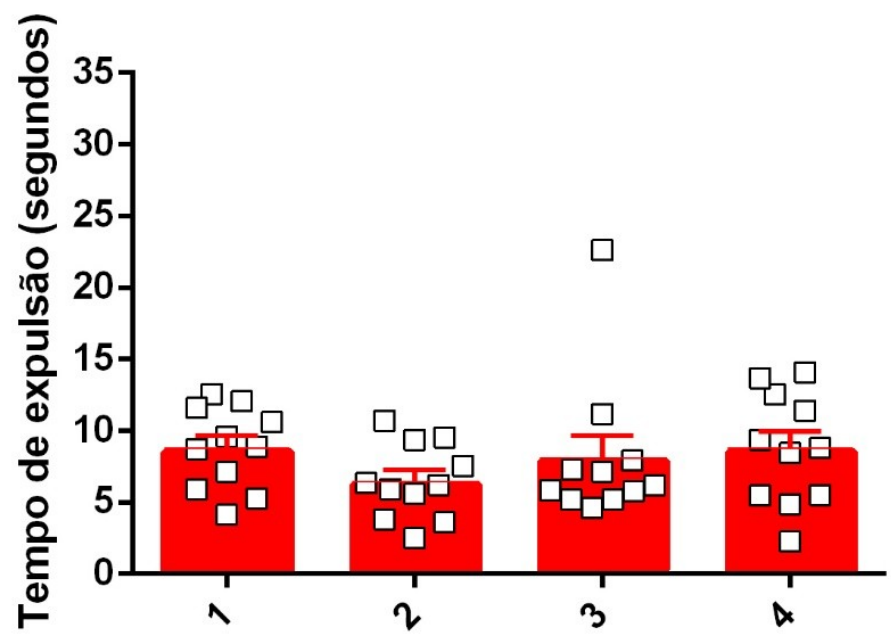

Fonte: LEITE, F. R. ${ }^{1,2}$, CARVALHO, A. M., ${ }^{1,2}$ ZANON, S²., LUCAS, G. ${ }^{1,2}$ (2019).

Nas Figuras 19 e 20- contêm a relação do comportamento de dominância em uma linha temporal de dor, na qual o macho dominante de um grupo de machos, assim como à fêmea dominante de um grupo de fêmeas, expulsara seus respectivos subordinados antes e após serem submetidos a estimulação dolorosa. No que diz respeito a associação de hierarquia social e dor, diferenças significativas entre o tempo que levou cada dominante para expulsar do tubo cada subordinado e o grau da intensidade dolorosa não foram observadas. Números dispostos no eixo x do gráfico representa à linha temporal da dor, nos quais 1,2, 3 e 4, respectivamente representam basal, 
seis horas, 24 horas (pico do processo nociceptivo) e sete dias de processo inflamatório. $p=0,49$ ( $\mathrm{n}=10$ - 11 por grupo) (19); $p=0,44$ (20) ( $\mathrm{n}=11$ por grupo). Cada barra representa à média \pm erro padrão, análise de variância de uma via. 


\section{DISCUSSÃO}

Nas últimas décadas, muitos trabalhos têm avançado no conhecimento fisiopatológico da dor, especialmente sob seu aspecto sensorial. No entanto, uma plena abordagem clínica da dor, que por si só, seja capaz de cessar processos nóxicos de maneira efetiva, ainda é um terreno obscuro, sobretudo, por ser este, um fenômeno integralmente multifacetado (NICK CHRISTELIS, 2017).

Por outro lado, este estudo realizado com camundongos, delineou a abordagem da percepção dolorosa ante o seu aspecto afetivo. Comportamentos nocifencivos foram evocados mediante o teste de formalina, elencados por diferentes paradigmas. Dado a ampla influência do componente social da dor na interpretação de sua intensidade (Tracy, 2017), foram investigadas neste trabalho, a capacidade de o contexto social não aversivo atuar na modulação do processo nóxico, assim como a existência de correlação entre determinado contexto social e a amplitude da expressão dos comportamentos nocifensivos. Além da posição de dominância em exposição a dor junto a seus subordinados.

Neste trabalho, foi possível constatar que, o contexto social exerce efetiva influência sobre a manifestação de comportamentos pertinentes a dor. Tanto o número de sacudidas, quanto o tempo de lambida da pata que recebera formalina, apresentaram diferenças significativas, sobretudo, evidenciadas quando se comparou, grupos que experimentaram dor junto a coespecíficos, com grupos de contexto social de isolamento (controles).

Ademais, a diferença mais marcante, se deu no contexto parental, em que à fêmea mãe, na presença de sua prole, exibiu minimamente os comportamentos nocifensivos, quando comparada a fêmea isolada (Fig. 5C e D), o que não foi observado no macho pai (Fig. 5A e B). Em paralelo, o contexto de gênero oposto, caracterizou-se da acentuada diferença, tanto para à fêmea, quanto para o macho que vivenciou a dor acompanhado de um coespecífico de gênero oposto (Fig. 3). No contexto de irmãos, verificou-se menor expressão do tempo de lambida apenas no macho que experimentou dor na companhia de seu irmão (Fig. 2B), o que não foi observado no número de sacudidas da pata (Fig. 2A). Para fêmeas, não foi verificado diferenças efetivas entre o contexto de isolamento e o contexto de irmãs no número de sacudidas (Fig. 2C) e no tempo de lambida a diferença se deu apenas na fase 1 do teste (Fig. 2D). Ainda além, no teste de formalina, diferenças entre o macho, e à fêmea que vivenciou a dor isoladamente, não foram constatadas (Fig. 1A e B). Na hierarquia de dominância, macho 
e fêmea não diferiu no tempo de expulsão de seus subordinados após submetidos a estimulação dolorosa (Fig. 6A e B)

De forma genérica, foi observado que os animais submetidos ao teste de formalina, apresentaram uma maior propensão em evocar a lambida do que à sacudida da pata afetada. Presumivelmente, pelo comportamento de lambida ser caracteristicamente mais espontâneo nestes animais do que a execução da sacudida, dessa forma é possível pressupor que para a sacudida, seja requerido uma estimulação nóxica potencialmente mais intensa.

O estudo em foco contou com algumas limitações, como o estresse do animal decorrente a sua manipulação, o qual empenhou-se a ser minimizado mediante ao cumprimento de adaptações diárias ao ambiente de experimentação. No momento das gravações, os experimentadores mantiveram-se ausentes do local, a fim de evitar interferências na resposta comportamental dos animais. Supostamente, no contexto de gênero oposto, o ciclo estral poderia ser fonte de influência direta na manifestação dos comportamentos nocifensivos. No entanto, por meio da citologia vaginal, foi possível abolir correlações entre comportamentos nocifensivos e ciclo estral das fêmeas. Em razão de suas sutilidades, desapercebidas, ou pseudo identificadas, às respostas nocifensivas exigem do observador expressiva acurácia visual. Tendo em vista a padronização das análises comportamentais, foi considerada a observação resultante de um único examinador. No contexto parental, talvez teria sido relevante a comparação entre à mãe que experimentou dor na presença da prole, com uma fêmea mãe e com dor, porém isolada. Do mesmo modo, ter comparado, tanto à fêmea, quanto o macho que vivenciou dor acompanhado (a) de um irmão (ã), com parceiros do mesmo gênero, no entanto, agora na companhia de um estranho. Neste último contexto mencionado, a fim de minimizar interferências hierárquicas, macho e fêmea dominante de cada grupo mediante ao teste do tubo foram identificados e excluídos do experimento. No teste do tubo, apenas um modelo de nocicepção foi abordado, a dor de origem inflamatória, por meio da administração de CFA, portanto modelos que evocassem dor de outras origens seriam admissíveis neste trabalho como, dor neuropática e dor pós-cirurgica mediante incisão plantar.

Os dados obtidos sugerem que o isolamento durante a experiência de dor aguda é capaz de otimizar a exibição do comportamento doloroso de maneira significativa, presumivelmemente, porque este contexto não contou com a presença de um coespecífico, o qual fosse responsável a desviar o foco da sensação dolorosa na ocasião. Considerando o 
contexto de isolamento como aquele com maior alta nos comportamentos nocifensivos, traços de semelhança foram observados em um estudo realizado em humanos, o qual demonstrou que a interação social reduziu a escala de dor aguda dos indivíduos. Os participantes acompanhados de um amigo, ou até mesmo de um estranho, mas que lhe oferecera apoio, relataram menor sensação de dor em comparação a participantes desacompanhados, ou em companhia de um parceiro indiferente (BROWN et al., 2003). Entretanto, outro trabalho com camundongos, mostrou que o isolamento a longo prazo, por período de 30 dias, foi eficaz, tanto no aumento do limiar da dor, quanto na diminuição da sensibilidade à mofina. Diferentemente de nosso trabalho, em que o animal se manteve isolado somente no decurso da experimentação, isto possivelmente se deva a adaptações de longo prazo ocorridas no sistema opioidérgico durante este período de isolamento social (COUDEREAU et al., 1997).

A menor manifestação do comportamento de lambida em machos irmãos, pode estar atrelada ao fato da companhia do irmão ser um foco de distração da dor, assim como a correlação da proximidade física de um familiar estar ligada a modulação da sensibilidade dolorosa. Em consonância, foi visto que na presença de um familiar ou colega de caixa, o camundongo tende a manifestar mais expressivamente sua dor, ao passo que na companhia de um estranho tais comportamento são significativamente inibidos (DAMATO; PAVONE, 1996; LANGFORD et al., 2006). Ainda além, foi observado por Langford e colaboradores, o comportamento de abordagem ao parceiro de gaiola que se encontrara em condição dolorosa, e inclusive, que efeito analgésico pode ser mediado por esta abordagem social. O nível de proximidade entre estes animais fora significativamente correlacionado com a redução da resposta nocifensiva do animal afetado, no qual se observou que quanto maior o período de convivência juntos, mais expressiva a modulação do comportamento nocifensivo nestes animais (LANGFORD et al., 2010). Por outro lado, fêmeas irmãs, que foram separadas no desmame, não demonstraram modificações no limiar de dor, quando expostas, mais tarde a seus irmãos previamente apartados (D’AMATO, 1997). O que aponta semelhanças entre às fêmeas irmãs de nosso estudo, as quais em presença de uma fêmea irmã, não mostraram sofrer influências marcantes no comportamento nocifensivo, quando comparadas às fêmeas que passaram pela dor isoladamente, dessa forma foi verificado que a presença de uma irmã foi indiferente para a exibição do comportamento doloroso da fêmea afetada. Porém o que diverge do trabalho citado anteriormente, é o fato de que as fêmeas irmãs de nosso estudo 
permaneceram juntas, do desmame ao dia do experimento. Provavelmente a presença de um familiar possa ter atuado desinibindo a manifestação destes comportamentos.

Com efeito, no paradigma de gênero oposto, o comportamento doloroso do macho foi modificado pela presença da fêmea, o que pode estar diretamente relacionado a intercorrência de comportamentos reprodutivos como, corte, reflexo flehmen, cópula, eventualmente, entre outros. Nessa perspectiva, ocorrências de analgesia copulatória, tanto em macho, quanto em fêmea foi descrita em estudos anteriores, no entanto o período analgésico se deu apenas no preciso momento da cópula (GÓMORA et al., 1994; GONZÁLEZMARISCAL; GÓMORA; BEYER, 1994). Paralamente, foi observado que mesmo submetidos a odores aversivos, como o de um cadáver, ratos machos não tinham seu comportamento copulatório inibido, demonstrando que um odor, ou condição aversiva, não é capaz de interferir sobre a motivação sexual destes machos (PFAUS et al., 2012). Além do mais, casuais comportamentos de corte no macho presumivelmente possibilitaram a menor expressão de seus comportamentos nocifensivos, uma vez que se leva em consideração a seletividade das fêmeas para com a saúde e integridade do macho como parceiro sexual (REYNOLDS; GROSS, 1990).

Foi observado ainda que ocasionalmente, a fêmea desempenhou o comportamento de abordagem do macho acometido, o que em parte corrobora com os achados de Langford, em que o comportamento de abordagem se dá em indivíduos familiares, porém incompatível com nossos dados pelo fato de o macho ser estranho e não familiar (LANGFORD, 2009). Em outro estudo foi observado uma redução no tempo despendido pela fêmea com dor na companhia de um macho, que previamente se destacara como favorito por ela, consequentemente marcando uma diminuição no comportamento de cópula neste paradigma. Contrariamente à fêmea, nenhuma diminuição do comportamento de cópula se observou no camundongo macho submetido a estimulação dolorosa (FARMER et al., 2014). Por outro lado, à fêmea com dor na companhia do macho, também mostrou redução em suas respostas nocifensivas. Foi observado que a fêmea adotou uma postura de alerta, evitando a aproximação do macho, mantendo-se com olhar fito no mesmo ante qualquer ameaça de abordagem, aparentemente, inviabilizando o comportamento de lambida, o que por consequência pôde ter favorecido a significante atenuação deste comportamento, especialmente nos primeiros momentos do teste (fase 1). 
Um achado muito relevante, foi a inibição acentuada do comportamento nocifensivo da fêmea na presença de sua prole. Tal circunstância, pode estar associada a traços evolutivos, nos quais o cuidado maternal, encontra-se proeminentemente mais desenvolvido do que o cuidado paternal. Isto pode ser explicado pela hipótese de que às fêmeas, diferentemente dos machos, dispõem de incentivo especial para o cuidado parental, haja visto à ampla energia prévia dedicada a produção de óvulos e o subsequente período gestacional, desse modo não seria viável que todo investimento inicial despendido ao gameta, e posteriormente, no caso de mamíferos, à gestação, fosse meramente desprezado (ALCOCK, 2011). Além do que, à fêmea possui a prerrogativa de carregar consigo seus próprios genes (QUELLER, 1997). Qualidades estas, potencialmente aptas a modular comportamentos de dor em benefício ao cuidado maternal. Do mesmo modo, a reduzida expressão de dor nestas fêmeas mães, pode estar atribuída à aferências de outra ordem, por exemplo os estímulos táteis vinculados ao comportamento maternal, como a sucção da prole e o repouso sobre os filhotes aglomerados (MELZACK, 1996). Paralelamente, machos pais na presença de seus filhotes, apresentaram redução na resposta nocifensiva somente na primeira fase do tempo de lambida, possivelmente por um efeito agudo, no qual à prole se apresentou como foco de distração a dor. Para mais, ao considerar características evolutivas do cuidado paternal, algumas desvantagens são impostas aos machos, como a paternidade incerta, em virtude de fêmeas na maior parte das espécies aceitarem esperma de mais de um indivíduo. Ao mesmo tempo, machos que propiciam cuidado paternal privam-se de novas oportunidades de fecundação, propagando consequentemente menor quantidade de seus genes (QUELLER, 1997).

Para mais, camundongos em contexto social não aversivo, em geral, manifestam menos comportamentos nocifensivos do que em contexto de isolamento social. Tal efeito, indiretamente, conjectura uma mediação de hipoalgesia. Por certo, fatores psicológicos intrínsecos ao ser humano, devido a sua grandeza e complexidade, limitam a comparação de seus comportamentos sociais com os de camundongos. No entanto, não é evidente, em sua essência, que comportamentos sociais humanos, sejam acentuadamente distintos dos de roedores e outros animais não humanos (SAPOLSKY, 2005; MARTIN; TUTTLE; MOGIL, 2014). Paralelamente, é possível ainda, assumir semelhanças neuroquímicas e genéticas nas interações sociais de roedores e humanos (MARTIN; TUTTLE; MOGIL, 2014).

Outro dado obtido, foi a manutenção do status de dominância, tanto no macho quanto na fêmea, que mesmo sob a vulnerabilidade do processo doloroso, foi mantido o 
comportamento de dominância, expulsando do tubo seus subordinados. Tal comportamento, caracteriza-se dá competição por acesso a recursos, neste caso o espaço territorial (TANSLEY et al., 2018; FAN et al., 2019). Este achado sugere uma robustez no padrão da hierarquia de dominância, na qual mesmo em condição de vulnerabilidade, dominantes foram efetivos contra seus subordinados. No entanto, é possível hipotetizar que outros modelos de nocicepção possam interferir no comportamento de dominância, a título de exemplo, a formalina, um modelo incisivamente agudo, no qual em detrimento a dominância o animal seria levado à manifestação de comportamentos nocifensivos, o que abre margem a novas investigações no campo da hierarquia de dominância em exposição a dor. 


\section{CONCLUSÃO}

Apoiado nestes resultados, o desenvolvimento do presente estudo possibilitou uma análise de como o componente social da dor em contexto não aversivo, pode modular a percepção dolorosa em camundongos. Além disso, também permitiu investigar a interferência da nocicepção na hierarquia social.

Nesse sentido, foi constatado que a presença do gênero oposto foi relevante para a interpretação do estímulo doloroso nestes animais, no qual tanto à fêmea, quanto o macho que vivenciou a dor em companhia do coespecífico do gênero oposto, manifestou menor quantidade de comportamentos nocifensivos em relação aqueles que experimentaram a dor isoladamente (1). Ademais, para o macho a presença de um irmão foi determinante apenas na expressão de uma resposta nocifensiva, ao passo que para fêmea sob estimulo doloroso a presença de uma irmã foi insignificante quanto a modificação de comportamentos nocifesivos, o que confere a companhia de um familiar, pouca relevância, quanto à intercorrências na dor alheia (2). Na relação mãe/prole e pai/prole foi verificado que para à mãe, à prole exerce robusta influência sobre sua dor, ao ponto de inibir significativamente a manifestação de seus comportamentos de dor. Um exemplo preciso de modulação social da dor. Entretanto no macho pai o mesmo não ocorreu, o que demonstra o dinamismo do aspecto social da percepção dolorosa (3). Ainda além, foi demonstrado que a dor persistente de origem inflamatória não foi capaz de inviabilizar a relação dominante/subordinado (4).

Estes resultados mostram que o contexto social relacionado ao gênero oposto, à prole e ao coespecífico familiar são determinantes para a interpretação da experiência dolorosa em camundongos, e podem assim ser usados como modelos experimentais para investigação de circuitarias neurais específicas associadas aos componentes sociais que influenciam a percepção do estímulo nociceptivo, conjecturando novos meios de abordar os distintos cenários da dor. 


\section{REFERÊNCIA:}

ADLER, N. E. et al. Relationship of subjective and objective social status with psychological and physiological functioning: preliminary data in healthy white women. Health Psychol, v. 19, n. 6, p. 586-92, Nov 2000. ISSN 0278-6133 (Print)0278-6133. Disponível em: < http://dx.doi.org/ >.

ALCOCK, John. Comportamento animal. Porto Alegr: Artmed, 2011. 606 p.

ARAKAWA, H.; BLANCHARD, D. C.; BLANCHARD, R. J. Colony formation of C57BL/6J mice in visible burrow system: identification of eusocial behaviors in a background strain for genetic animal models of autism. Behav Brain Res, v. 176, n. 1, p. 27-39, Jan 10 2007. ISSN 0166-4328 (Print)0166-4328. Disponível em: < http://dx.doi.org/10.1016/j.bbr.2006.07.027 >.

BASBAUM, A. I. et al. Cellular and molecular mechanisms of pain. Cell, v. 139, n. 2, p. 267-84, Oct 16 2009. ISSN 0092-8674. Disponível em: < http://dx.doi.org/10.1016/j.cell.2009.09.028 >.

BENEDETTI, F. Placebo effects: from the neurobiological paradigm to translational implications. Neuron, v. 84, n. 3, p. 623-37, Nov 5 2014. ISSN 0896-6273. Disponível em: < http://dx.doi.org/10.1016/j.neuron.2014.10.023 >.

BONICA, J. J. Evolution and current status of pain programs. J Pain Symptom Manage, v. 5, n. 6, p. 368-74, Dec 1990. ISSN 0885-3924 (Print)0885-3924. Disponível em: < http://dx.doi.org/ >.

BRENNAN, T. J.; VANDERMEULEN, E. P.; GEBHART, G. F. Characterization of a rat model of incisional pain. Pain, v. 64, n. 3, p. 493-501, Mar 1996. ISSN 0304-3959 (Print)0304-3959. Disponível em: 〈 http://dx.doi.org/ > .

BROWN, Jennifer L. et al. Social Support na Experomental Pain. Psychosomatic Medicine, [s.1.], v. 65, n. 2, p.276-283, mar. 2003. Ovid Technologies (Wolters Kluwer Health). Disponível em: < http://dx.doi.org/10.1097/01.psy.0000030388.62434.46>.

BUSHNELL, M. C.; CEKO, M.; LOW, L. A. Cognitive and emotional control of pain and its disruption in chronic pain. Nat Rev Neurosci, v. 14, n. 7, p. 502-11, Jul 2013. ISSN 1471003x. Disponível em: < http://dx.doi.org/10.1038/nrn3516

$>$.

COUDEREAU, Jean-pierre et al. Effect of isolation on pain threshold and on different effects of morphine. Progress In Neuro-psychopharmacology And Biological Psychiatry, [s.1.], v. 21, n. 6, p.997-1018, ago. 1997. Elsevier BV. Disponível em: < http://dx.doi.org/10.1016/s0278-5846(97)00094-8 >. 
CODERRE, T. J.; VACCARINO, A. L.; MELZACK, R. Central nervous system plasticity in the tonic pain response to subcutaneous formalin injection. Brain Res, v. 535, n. 1, p. 155-8, Dec 3 1990. ISSN 0006-8993 (Print)0006-8993. Disponível em: < http://dx.doi.org/ >.

COLE, B. J. Dominance hierarchies in leptothorax ants. Science, v. 212, n. 4490, p. 83-4, Apr 3 1981. ISSN 0036-8075 (Print)0036-8075. Disponível em: < http://dx.doi.org/10.1126/science.212.4490.83 >.

COLLOCA, L.; BENEDETTI, F. Placebos and painkillers: is mind as real as matter? Nat Rev Neurosci, v. 6, n. 7, p. 545-52, Jul 2005. ISSN 1471-003X (Print)1471-003x. Disponível em: $<$ http://dx.doi.org/10.1038/nrn1705 $>$.

CORA, M. C.; KOOISTRA, L.; TRAVLOS, G. Vaginal Cytology of the Laboratory Rat and Mouse: Review and Criteria for the Staging of the Estrous Cycle Using Stained Vaginal Smears. Toxicol Pathol, v. 43, n. 6, p. 776-93, Aug 2015. ISSN 0192-6233. Disponível em: < http://dx.doi.org/10.1177/0192623315570339 >.

D'AMATO, Francesca R.; PAVONE, Flaminia. Reunion of Separated Sibling Mice: Neurobiological and Behavioral Aspects. Neurobiology Of Learning And Memory, [s.1.], v. 65, n. 1, p.9-16, jan. 1996. Elsevier BV. Disponível em: < http://dx.doi.org/10.1006/nlme.1996.0002>.

D'AMATO, Francesca R.. Neurobiological and Behavioral Aspects of Recognition in Female Mice. Physiology \& Behavior, [s.1.], v. 62, n. 6, p.1311-1317, dez. 1997. Elsevier BV. Disponível em: < http://dx.doi.org/10.1016/s0031-9384(97)00343-0 >.

DJOUHRI, L. et al. Partial nerve injury induces electrophysiological changes in conducting (uninjured) nociceptive and nonnociceptive DRG neurons: Possible relationships to aspects of peripheral neuropathic pain and paresthesias. Pain, v. 153, n. 9, p. 1824-36, Sep 2012. ISSN 0304-3959. Disponível em: < http://dx.doi.org/10.1016/j.pain.2012.04.019 >.

DUBUISSON, D.; DENNIS, S. G. The formalin test: a quantitative study of the analgesic effects of morphine, meperidine, and brain stem stimulation in rats and cats. Pain, v. 4, n. 2, p. 161-74, Dec 1977. ISSN 0304-3959 (Print)03043959. Disponível em: 〈 http://dx.doi.org/ >.

DUNBAR, R. I.; DUNBAR, E. P. Dominance and reproductive success among female gelada baboons. Nature, v. 266, n. 5600, p. 351-2, Mar 24 1977. ISSN 0028-0836 (Print)0028-0836. Disponível em: < http://dx.doi.org/ >

EISENBERGER, N. I.; LIEBERMAN, M. D.; WILLIAMS, K. D. Does rejection hurt? An FMRI study of social exclusion. Science, v. 302, n. 5643, p. 290-2, Oct 10 2003. ISSN 00368075. Disponível em: < http://dx.doi.org/10.1126/science.1089134 >.

FAN, Z. et al. Using the tube test to measure social hierarchy in mice. Nat Protoc, v. 14, n. 3, p. 819-831, Mar 2019. ISSN 1750-2799. Disponível em: < http://dx.doi.org/10.1038/s41596$\underline{018-0116-4}>$. 
FARMER, M. A. et al. Pain Reduces Sexual Motivation in Female But Not Male Mice. Journal Of Neuroscience, [s.1.], v. 34, n. 17, p.5747-5753, 23 abr. 2014. Society for Neuroscience. Disponível em: < http://dx.doi.org/10.1523/jneurosci.5337-13.2014 >.

FEHRENBACHER, J. C.; VASKO, M. R.; DUARTE, D. B. Models of Inflammation: Carrageenan- or Complete Freund's Adjuvant-Induced Edema and Hypersensitivity in the Rat. Curr Protoc Pharmacol, v. 0 5, p. Unit5 4, Mar 2012. ISSN 1934-8282 (Print)1934-8290 (Electronic). Disponível em: < http://dx.doi.org/10.1002/0471141755.ph0504s56 >.

FISCHER, M. et al. The interphase of the formalin test. Pain, v. 155, n. 3, p. 511-21, Mar 2014. ISSN 0304-3959.

FREUND, J. Some Aspects of Active Immunization. Annual Review Of Microbiology, [s.1.], v. $1, \quad$ n. $1, \quad$ p.291-308, out. 1947. Annual Reviews. http://dx.doi.org/10.1146/annurev.mi.01.100147.001451.

GEERS, A. L. et al. Further evidence for individual differences in placebo responding: an interactionist perspective. J Psychosom Res, v. 62, n. 5, p. 563-70, May 2007. ISSN 00223999 (Print)0022-3999. Disponível em: < http://dx.doi.org/10.1016/j.jpsychores.2006.12.005 $>$.

GÓMORA, P. et al. Momentary analgesia produced by copulation in female rats. Brain Research, [s.1.], v. 656, n. 1, p.52-58, set. 1994. Elsevier BV. Disponível em: < http://dx.doi.org/10.1016/0006-8993(94)91365-x >.

GONZÁLEZ-MARISCAL, Gabriela; GÓMORA, Porfirio; BEYER, Carlos. Participation of opiatergic, GABAergic, and serotonergic systems in the expression of copulatory analgesia in male rats. Pharmacology Biochemistry And Behavior, [s.1.], v. 49, n. 2, p.303-307, out. 1994. Elsevier BV. Disponível em: < http://dx.doi.org/10.1016/0091-3057(94)90425-1 >.

HARKINS, S. W.; PRICE, D. D.; BRAITH, J. Effects of extraversion and neuroticism on experimental pain, clinical pain, and illness behavior. Pain, v. 36, n. 2, p. 209-18, Feb 1989. ISSN 0304-3959 (Print)0304-3959. Disponível em: 〈 http://dx.doi.org/ > .

HUNSKAAR, S.; FASMER, O. B.; HOLE, K. Formalin test in mice, a useful technique for evaluating mild analgesics. J Neurosci Methods, v. 14, n. 1, p. 69-76, Jun 1985. ISSN 01650270 (Print)0165-0270. Disponível em: < http://dx.doi.org/ > .

JENNINGS, E. M. et al. Stress-induced hyperalgesia. Prog Neurobiol, v. 121, p. 1-18, Oct 2014. ISSN 0301-0082. Disponível em: < http://dx.doi.org/10.1016/j.pneurobio.2014.06.003 $>$.

JOHANEK, L. M. et al. A Role for Polymodal C-Fiber Afferents in Nonhistaminergic Itch. J Neurosci, v. 28, n. 30, p. 7659-69, Jul 23 2008. ISSN

0270-6474 (Print)1529-2401 (Electronic)

Disponível em:

http://dx.doi.org/10.1523/jneurosci.1760-08.2008 >. 
LANGFORD, D. J. et al. Social modulation of pain as evidence for empathy in mice. Science, v. 312, n. 5782, p. 1967-70, Jun 30 2006. ISSN 0036-8075. Disponível em: < http://dx.doi.org/10.1126/science.1128322 >.

Social approach to pain in laboratory mice. Soc Neurosci, v. 5, n. 2, p.

163-70, 2010. ISSN 1747-0919. Disponível em: < http://dx.doi.org/10.1080/17470910903216609 >.

LEONARD, M. T.; CANO, A.; JOHANSEN, A. B. Chronic Pain in a Couples Context: A Review and Integration of Theoretical Models and Empirical Evidence. J Pain, v. 7, n. 6, p. 377-90, Jun 2006. ISSN 1526-5900 (Print). Disponível em: < http://dx.doi.org/10.1016/j.jpain.2006.01.442 >.

LINDZEY, G.; WINSTON, H.; MANOSEVITZ, M. Social dominance in inbred mouse strains. Nature, v. 191, p. 474-6, Jul 29 1961. ISSN 0028-0836 (Print)0028-0836. Disponível em: < http://dx.doi.org/ >.

LONSTEIN, J. S.; DE VRIES, G. J. Sex differences in the parental behavior of rodents. Neurosci Biobehav Rev, v. 24, n. 6, p. 669-86, Aug 2000. ISSN 01497634 (Print)0149-7634. Disponível em: < http://dx.doi.org/ >.

LONSTEIN, J. S.; FLEMING, A. S. Parental behaviors in rats and mice. Curr Protoc Neurosci, v. Chapter 8, p. Unit 8.15, Feb 2002. ISSN 1934-8576. Disponível em: < http://dx.doi.org/10.1002/0471142301.ns0815s17 >.

MACKENBACH, J. P. Mind the gap--hierarchies, health and human evolution. Int J Epidemiol, v. 31, n. 3, p. 684, Jun 2002. ISSN 0300-5771 (Print)03005771. Disponível em: < http://dx.doi.org/ >.

MARTIN, Loren J.; TUTTLE, Alexander H.; MOGIL, Jeffrey S.. The Interaction Between Pain and Social Behavior in Humans and Rodents. Behavioral Neurobiology Of Chronic Pain, [s.1.], p.233-250, 2014. Springer Berlin Heidelberg. Disponível em: < http://dx.doi.org/10.1007/7854_2014_287>.

MCCALL, W. D.; TANNER, K. D.; LEVINE, J. D. Formalin induces biphasic activity in Cfibers in the rat. Neurosci Lett, v. 208, n. 1, p. 45-8, Apr 12 1996. ISSN 0304-3940 (Print)0304-3940. Disponível em: < http://dx.doi.org/ >.

MCDERMOTT, A. M. et al. The burden of neuropathic pain: results from a cross-sectional survey. Eur J Pain, v. 10, n. 2, p. 127-35, Feb 2006. ISSN

1090-3801 (Print)1090-3801. Disponível em: < http://dx.doi.org/10.1016/j.ejpain.2005.01.014 $>$.

MELZACK, Ronald. Gate control theory. Pain Forum, [s.1.], v. 5, n. 2, p.128-138, jun. 1996. Elsevier BV. Disponível em: < http://dx.doi.org/10.1016/s1082-3174(96)80050-x >.

MELZACK, R. From the gate to the neuromatrix. Pain, v. Suppl 6, p. S121-6, Aug 1999. ISSN 0304-3959 (Print)0304-3959. Disponível em: < http://dx.doi.org/ > . 
MERLOT, E. et al. The rank assessed in a food competition test influences subsequent reactivity to immune and social challenges in mice. Brain Behav Immun, v. 18, n. 5, p. 46875, Sep 2004. ISSN 0889-1591 (Print)0889-1591. Disponível em: < http://dx.doi.org/10.1016/j.bbi.2003.11.007 >.

NICK CHRISTELIS. Neuropathy, Neuropathic Pain, and Painful Peripheral Neuropathy. Neuromodulation, Richmond, v. 8, n. 17, p.2-6, ago. 2017.

OBATA, K. et al. Contribution of degeneration of motor and sensory fibers to pain behavior and the changes in neurotrophic factors in rat dorsal root ganglion. Exp Neurol, v. 188, n. 1, p. 149-60, Jul 2004. ISSN 0014-4886

(Print)0014-4886. Disponível em: 〈 http://dx.doi.org/10.1016/j.expneurol.2004.03.012 >.

PFAUS, James G. et al. Who, What, Where, When (and Maybe Even Why)? How the Experience of Sexual Reward Connects Sexual Desire, Preference, and Performance. Archives Of Sexual Behavior, [s.1.], v. 41, n. 1, p.31-62, fev. 2012. Springer Science and Business Media LLC. Disponível em: < http://dx.doi.org/10.1007/s10508-0129935-5>.

PLOGHAUS, A. et al. Exacerbation of pain by anxiety is associated with activity in a hippocampal network. J Neurosci, v. 21, n. 24, p. 9896-903, Dec 15 2001. ISSN 0270-6474. Disponível em: < http://dx.doi.org/ >.

. Dissociating pain from its anticipation in the human brain. Science, v.

284, n. 5422, p. 1979-81, Jun 18 1999. ISSN 0036-8075 (Print)0036-8075. Disponível em: < http://dx.doi.org/ >.

PORRO, C. A.; CAVAZZUTI, M. Spatial and temporal aspects of spinal cord and brainstem activation in the formalin pain model. Prog Neurobiol, v. 41, n. 5, p. 565-607, Nov 1993. ISSN 0301-0082 (Print)0301-0082. Disponível em: < http://dx.doi.org/ > .

PRICE, D. D.; BARRELL, J. J. Mechanisms of analgesia produced by hypnosis and placebo suggestions. Prog Brain Res, v. 122, p. 255-71, 2000. ISSN 0079-6123 (Print)0079-6123. Disponível em: < http://dx.doi.org/ >.

PRICE, D. D.; FINNISS, D. G.; BENEDETTI, F. A comprehensive review of the placebo effect: recent advances and current thought. Annu Rev Psychol, v. 59, p. 565-90, 2008. ISSN 0066-4308 (Print)0066-4308. Disponível em: http://dx.doi.org/10.1146/annurev.psych.59.113006.095941 >.

PRICE, D. D. et al. A simultaneous comparison of fentanyl's analgesic effects on experimental and clinical pain. Pain, v. 24, n. 2, p. 197-203, Feb 1986. ISSN 0304-3959 (Print)0304-3959. Disponível em: < http://dx.doi.org/ >. 
An analysis of factors that contribute to the magnitude of placebo analgesia in an experimental paradigm. Pain, v. 83, n. 2, p. 147-56, Nov 1999. ISSN 0304-3959 (Print)03043959. Disponível em: < http://dx.doi.org/ >.

QU, C. et al. An Integrative Interdisciplinary Perspective on Social Dominance Hierarchies. Trends Cogn Sci, v. 21, n. 11, p. 893-908, Nov 2017. ISSN 13646613. Disponível em: < http://dx.doi.org/10.1016/j.tics.2017.08.004 >.

QUELLER, David C.. Why do females care more than males? Proceedings Of The Royal Society Of London. Series B: Biological Sciences, [s.1.], v. 264, n. 1388, p.1555-1557, 22 nov. 1997. The Royal Society. Disponível em: < http://dx.doi.org/10.1098/rspb.1997.0216 >.

REYNOLDS, John D.; GROSS, Mart R.. Costs and Benefits of Female Mate Choice: Is There a Lek Paradox?. The American Naturalist, [s.1.], v. 136, n. 2, p.230-243, ago. 1990. University of Chicago Press. Disponível em: < http://dx.doi.org/10.1086/285093 >.

RIEDEL, W.; NEECK, G. Nociception, pain, and antinociception: current concepts. Z Rheumatol, v. 60, n. 6, p. 404-15, Dec 2001. ISSN 0340-1855 (Print)0340-1855. Disponível em: < http://dx.doi.org/ $>$.

ROCHA, Anita Perpétua Carvalho et al. Dor: aspectos atuais da sensibilização periférica e central. Revista Brasileira de Anestesiologia, [s.1.], v. 57, n. 1, p.94-105, fev. 2007. Elsevier BV. http://dx.doi.org/10.1590/s003470942007000100011.

SAPOLSKY, R. M. The influence of social hierarchy on primate health. Science, v. 308, n. 5722, p. 648-52, Apr 29 2005. ISSN 0036-8075. Disponível em: < http://dx.doi.org/10.1126/science.1106477 >.

SAPOLSKY, R. M.; ROMERO, L. M.; MUNCK, A. U. How do glucocorticoids influence stress responses? Integrating permissive, suppressive, stimulatory, and preparative actions. Endocr Rev, v. 21, n. 1, p. 55-89, Feb 2000. ISSN

0163-769X (Print)0163-769x. Disponível em: 〈 http://dx.doi.org/10.1210/edrv.21.1.0389 >.

SAWAMOTO, N. et al. Expectation of pain enhances responses to nonpainful somatosensory stimulation in the anterior cingulate cortex and parietal operculum/posterior insula: an eventrelated functional magnetic resonance imaging study. J Neurosci, v. 20, n. 19, p. 7438-45, Oct 1 2000. ISSN 02706474. Disponível em: < http://dx.doi.org/ >.

STEIN, C.; MILLAN, M. J.; HERZ, A. Unilateral inflammation of the hindpaw in rats as a model of prolonged noxious stimulation: alterations in behavior and nociceptive thresholds. Pharmacol Biochem Behav, v. 31, n. 2, p. 445-51, Oct 1988. ISSN 0091-3057 (Print)00913057. Disponível em: < http://dx.doi.org/ >. 
TANSLEY, Shannon N. et al. Modulation of social behavior and dominance status by chronic pain in mice. Genes, Brain And Behavior, [s.1.], v. 18, n. 1, p.1-6, 19 set. 2018. Wiley. Disponível em: < http://dx.doi.org/10.1111/gbb.12514 >.

TRACY, Lincoln M.. Psychosocial factors and their influence on the experience of pain. Pain Reports, [s.1.], v. 2, n. 4, p.846-855, 2017. Ovid Technologies (Wolters Kluwer Health). Disponível em: < http://dx.doi.org/10.1097/pr9.0000000000000602 >.

TREEDE, R. D. The International Association for the Study of Pain definition of pain: as valid in 2018 as in 1979, but in need of regularly updated footnotes. In:

(Ed.). Pain Rep, v.3, 2018. ISBN 2471-2531 (Electronic).

VILLEMURE, C.; BUSHNELL, M. C. Cognitive modulation of pain: how do attention and emotion influence pain processing? Pain, v. 95, n. 3, p. 195-9, Feb 2002. ISSN 0304-3959 (Print)0304-3959. Disponível em: 〈 http://dx.doi.org/ >

WADE, J. B. et al. Assessing the stages of pain processing: a multivariate analytical approach. Pain, v. 68, n. 1, p. 157-67, Nov 1996. ISSN 0304-3959 (Print)0304-3959. Disponível em: < http://dx.doi.org/ >

A canonical correlation analysis of the influence of neuroticism and extraversion on chronic pain, suffering, and pain behavior. Pain, v. 51, n. 1, p. 67-73, Oct 1992. ISSN 03043959 (Print)0304-3959. Disponível em: < http://dx.doi.org/ >.

WADE, J. B.; HART, R. P. Attention and the stages of pain processing. Pain Med, v. 3, n. 1, p. 30-8, Mar 2002. ISSN 1526-2375 (Print)1526-2375.

Disponível em: < http://dx.doi.org/10.1046/j.1526-4637.2002.02008.x >.

WANG, F.; KESSELS, H. W.; HU, H. The mouse that roared: neural mechanisms of social hierarchy. Trends Neurosci, v. 37, n. 11, p. 674-82, Nov

2014. ISSN 0166-2236. Disponível em: < http://dx.doi.org/10.1016/j.tins.2014.07.005 >.

WILLIAMS, A. C.; CRAIG, K. D. Updating the definition of pain. Pain, v. 157, n. 11, p. 2420-2423, Nov 2016. ISSN 0304-3959. Disponível em: < http://dx.doi.org/10.1097/j.pain.0000000000000613 >.

YAKSH, T. L. et al. An automated flinch detecting system for use in the formalin nociceptive bioassay. J Appl Physiol (1985), v. 90, n. 6, p. 2386-402, Jun 2001. ISSN 8750-7587 (Print)0161-7567. Disponível em: < http://dx.doi.org/10.1152/jappl.2001.90.6.2386 >. 